\title{
Wave-current dynamics and interactions near the two inlets of a shallow lagoon-inlet-coastal ocean system under hurricane conditions
}

\author{
Miaohua Mao, Meng Xia* \\ Department of Natural Sciences, University of Maryland Eastern Shore, MD 21853, USA
}

\section{A R T I C L E I N F O}

\section{Keywords:}

Hurricane conditions

Inlet dynamics

Numerical modeling

Wave dynamics

Wave-current interactions

\begin{abstract}
A B S T R A C T
Inlet wave-current dynamics and interactions are vital to the physical exchanges in a lagoon-inlet-coastal ocean system. A wave-current coupled model was calibrated and validated against observational data, and then applied to investigate the complex dynamics in the Maryland Coastal Bays during Hurricane Irene (2011). With the inclusion of wave-current interactions, skill in simulating the maximum total water surface elevation was improved under hurricane conditions. Major processes of wave-current interactions include the radiation stressinduced setup and current, and water depth variation-induced wave breaking. Wave-induced bottom friction and sea surface roughness are of secondary importance to nearshore dynamics. Further investigations reveal that tidal currents and ocean swells dominate inlet circulation and wave dynamics, respectively. Physical dynamics within the paired inlets are regulated by local winds, wave-current interactions, and unique inlet characteristics. However, wave dynamics in the lagoon and behind inlets are dominated by local winds and modulated by the shallow bathymetry. With the hypothetical closure of any inlet, wave-current dynamics and interactions behind the corresponding inlet are strongly altered, whereas they are weakly influenced from a remote one. Occasionally, the circulation near the narrow Ocean City Inlet area is influenced moderately by artificially shutting down the relatively wider Chincoteague Inlet. The finding from this work on the Maryland Coastal Bays can be beneficial to understanding similar lagoon-inlet-coastal ocean systems elsewhere.
\end{abstract}

\section{Introduction}

Inlet and its wave-current dynamics are critical to the residence time (Defne and Ganju, 2015), particle transport (Xia et al., 2011), drifter spreading (Spydell et al., 2015), and material exchanges (Allen et al., 2007; Ferrarin et al., 2013; Umgiesser et al., 2014; Kang et al., 2017) in a lagoon-inlet-coastal ocean system. Based on the relationship between tidal ranges and mean wave heights, inlets are classified into three types: tide-dominated, wave-dominated, and mixed-energy (Hayes, 1979). Given the complexity and significance of wave-current dynamics, wave-dominated inlet has been studied intensively over the past decade (van der Westhuysen et al., 2012). Previous work indicated that inlet dynamics are synergistically controlled by ocean swells, tidal currents, local winds, bottom friction, and depth-induced wave breaking (Olabarrieta et al., 2011; Ganju et al., 2017). Additionally, comprehensive and accurate predictions of the inlet dynamics for practical applications and scientific curiosity require the consideration of wave-current interactions (Bertin et al., 2009; Chen et al., 2015; Beudin et al., 2017).

The theory of wave-current interactions was established by
Longuet-Higgins and Stewart (1964), who proposed that two-dimensional (2D), depth-averaged wave radiation stress is responsible for generating the wave-induced setup and longshore currents in the surf zone. This proposal was verified by observations in the shallow regions of North Carolina (Lentz et al., 1999; Lentz and Raubenheimer, 1999), Kaneohe Bay, Hawaii (Lowe et al., 2009), and the Red Sea (Lentz et al., 2016). Perrie et al. (2003) determined that the conversion of excessive momentum fluxes from waves to surface currents begins to take effect during intense storms. Recently, Mellor (2005, 2013, 2015) extended the work of Longuet-Higgins and Stewart (1964) and derived vertically dependent equations of radiation stress. Subsequently, the significance of this newly developed three-dimensional (3D) radiation stress was recognized in shallow-water dynamics from idealized numerical experiments (Ji et al., 2018 selecting the latest Mellor, 2015) and practical applications (Sheng and Liu, 2011 using Mellor, 2008; Ge et al., 2013 and Niu and Xia, 2017 adopting Mellor, 2005; Marsooli et al., 2017 and Niu et al., 2018 applying Mellor, 2015). In addition to radiation stress, wave effects that include the wave-induced sea surface roughness (Donelan et al., 1993) and bottom friction (Madsen, 1994) were reported to have an impact on the circulation in the South Atlantic

\footnotetext{
* Corresponding author.

E-mail address: mxia@umes.edu (M. Xia).
} 
Bight (Xie et al., 2003) and Lake Erie (Niu and Xia, 2017). Previous work in the southern North Sea (Wolf and Prandle, 1999), an idealized tidal estuary (Lin and Perrie, 2003), Charleston Harbor, South Carolina (Liu and Xie, 2009), and Mackenzie Delta, Canada (Xu et al., 2013) further demonstrated that the water depth variation in the shallow water substantially modulated the wave breaking intensity.

However, little attention has been paid to the wave-current dynamics and interactions at the inlet of a lagoon-inlet-coastal ocean system, which are often considered to be highly intense and complex (Dodet et al., 2013). Using a morphodynamic model, MORSYS2D, Bertin et al., (2009) detected that radiation stress-induced setup at the Óbidos Inlet (Portugal) accounted for $10 \%$ of significant wave height in the offshore region. Malhadas et al., (2009) made additional remarks that the magnitude of wave-induced setup was strongly associated with the unique inlet characteristics. More recently, wave-current interactions that occurred mainly in shallow regions have been closely examined in the Albufeira Lagoon, Portugal (Dodet et al., 2013), the semienclosed Venice Lagoon, Italy (Benetazzo et al., 2013), and the New River Inlet, North Carolina (Chen et al., 2015). However, previous studies focused primarily on single-inlet systems (Bertin et al., 2009; Malhadas et al., 2009; Dodet et al., 2013) instead of the more complicated double-inlet systems, in which the dynamic interconnection between the inlets ought to be given more consideration (Pacheco et al., 2010; Orescanin et al., 2014; Duran-Matute et al., 2016). Field observations and numerical simulations at Katama Inlet, Massachusetts (Orescanin et al., 2014) indicate that the wave-induced setup in this double-inlet system, which is reduced due to the opening of the remote inlet, is lower than that from a typical single-inlet system. The conceptual model used by Orescanin et al. (2014), however, is limited within an idealized system owing to the simplification of model domain and the assumption of a uniform wind field. Using the unstructuredgrid-based model with spatiotemporally varying winds, Fabião et al. (2016) and Kang et al. (2017) identified that wind direction significantly impacts water exchanges of the complex multipleinlet system, especially under strong wind conditions. However, both models were tested in the absence of waves, which play a prominent role in the inlet circulation and should be taken into account (Wargula et al., 2014).

In this work, the high-resolution, unstructured-grid-based, 3D, wave-current coupled modeling system FVCOM/SWAVE (Finite-Volume Community Ocean Model/Surface Wave Model; Chen et al., 2013) was applied to the paired inlets of a shallow lagoon-inlet-coastal ocean system (i.e., Maryland Coastal Bays) under hurricane conditions. Remaining sections of this paper are organized as follows: Section 2 introduces the methodology, which includes the model grid, coupling process, model inputs, and experimental design; Section 3 assesses the model skill in wave-current simulations; Section 4 discusses the inlet wave-current dynamics, which include the effects of tides, ocean swells, local winds, inlet closure, and wave-current interactions; Section 5 presents the conclusions.

\section{Methodology}

\subsection{Model domain and grid}

The Maryland Coastal Bays (MCBs; total area of $\sim 282 \mathrm{~km}^{2}$ ) are located along the Atlantic coast of Virginia, Maryland, and Delaware (Boynton et al., 1996). They encompass five sub-bays that include Assawoman Bay, Isle of Wight Bay (upper bays), Sinepuxent Bay, Newport Bay, and Chincoteague Bay (lower Bays), see Fig. $1 \mathrm{a}$ and Kang et al. (2017). The MCBs communicate with the adjacent Atlantic Ocean via the Ocean City Inlet (OCI) and Chincoteague Inlet (CI). The paired inlets separate Fenwick and Assateague Islands, and connect Chincoteague Bay with the coastal ocean (Pritchard, 1960). The width and length of the small OCI are $0.2-0.4 \mathrm{~km}$ by $1 \mathrm{~km}$, compared to $1 \mathrm{~km}$ by $3 \mathrm{~km}$ for the larger CI. The principal axis of the MCBs follows a southwestern-northeastern direction, which is perpendicular to the OCI and parallel with the CI (Fig. 1a-c). The water depths of the inner bays behind the CI (e.g., Bogues Bay, Watts Bay, Toms Cove, and Shelly Bay) are shallow and less than $2 \mathrm{~m}$ but increase to 9.3 and $7.6 \mathrm{~m}$ in the navigational channels of the OCI and CI, respectively (Boynton et al., 1993; Wazniak et al., 2005). Because of a low freshwater discharge (Dillow and Greene, 1999), micro-tide (0-2 m) and mild wave climate, the paired inlets of the MCBs are wave-dominated (Krantz et al., 2009). To resolve the highly variable bathymetry and complex geometry of coasts, islands, tidal channels, and inlets, unstructured grids (7332 nodes and 12,428 elements) with variable sizes and orientations are used in the numerical model (Fig. 1d-h). Grid sizes are less than $10 \mathrm{~m}$ in the shallow regions and up to $1.74 \mathrm{~km}$ along the open boundary.

\subsection{Descriptions of the modeling system}

The wave-current coupled system allows for the computation of depth-induced wave breaking with the inclusion of water depth variation in the wave model. This system also includes the wave-induced radiation stress, bottom friction, and sea surface roughness in the momentum balance equation of the circulation model. In the surf zone, conversion of the excessive momentum fluxes from waves to currents caused by wave breaking is expressed as the radiation stress divergence (Longuet-Higgins and Stewart, 1964; Longuet-Higgins, 1970; Lane et al., 2007). Radiation stress gradients generated by wave breaking can induce a setup near the shoreline (Orescanin et al., 2014) and generate longshore currents when incident waves approach the beach at an oblique angle (Apotsos et al., 2008; Wargula et al., 2014). In order to fully represent the 3D wave-current interactions, expressions of the wave breaking process and radiation stress were further included in the vortex force formulism (Craik and Leibovich, 1976; McWilliams et al., 2004) and 3D radiation stress-based theory (Mellor, 2005), respectively. The aforementioned expressions were separately incorporated into the recently developed 3D wave-current coupled modeling systems known as the COAWST (Coupled-Ocean-Atmosphere-Wave-Sediment Transport; Kumar et al., 2012) and FVCOM/SWAVE (Finite-Volume Community Ocean Model/Surface Wave Model; Chen et al., 2013). Scientific debates over the advantages and limitations of the paired wave-current theories have been carried out since the past decade, and no consensus has been reached so far (Ardhuin et al., 2017; Mellor, 2015, 2016, 2017). Mellor (2013) proposed a criterion to test whether the application of the 3D radiation stress method was appropriate in a particular region (i.e., $\left[\frac{\partial h}{\partial x} / \sinh (k D)\right]^{2}$ is at the same order or smaller than $(k a)^{2}$, where the water column depth $D$ is the summation of the depth $h$ and phased-averaged, free surface elevation $\hat{\eta}$ ). This criterion was satisfied in most of the regions over the MCBs during Hurricane Irene (2011) and a similar system in the East Frisian Wadden Sea under storm conditions (Grashorn et al., 2015). Given that Mao and Xia (2017) and Niu and Xia (2017) successfully applied the 3D radiation stress-based (Mellor, 2005) FVCOM/SWAVE to the Great Lakes (note: Niu et al., 2018 applied Mellor, 2015), this study extended the application of this model to the MCBs and their paired inlets. In addition, modeled results from the updated 3D radiation stress formulation of Mellor (2015) were compared with the 2D version in Section 4.3. Detailed descriptions of the wave-current coupled FVCOM/SWAVE model were discussed below.

Wave-induced radiation stress gradients $\left(F_{x}, F_{y}\right)$ in the 2D FVCOM (Chen et al., 2013) are based on the theory proposed by LonguetHiggins and Stewart (1964):

$\left\{\begin{array}{l}F_{x}=-\frac{\partial S_{x x}}{\partial x}-\frac{\partial S_{x y}}{\partial y} \\ F_{y}=-\frac{\partial S_{x y}}{\partial x}-\frac{\partial S_{y y}}{\partial y},\end{array}\right.$ 

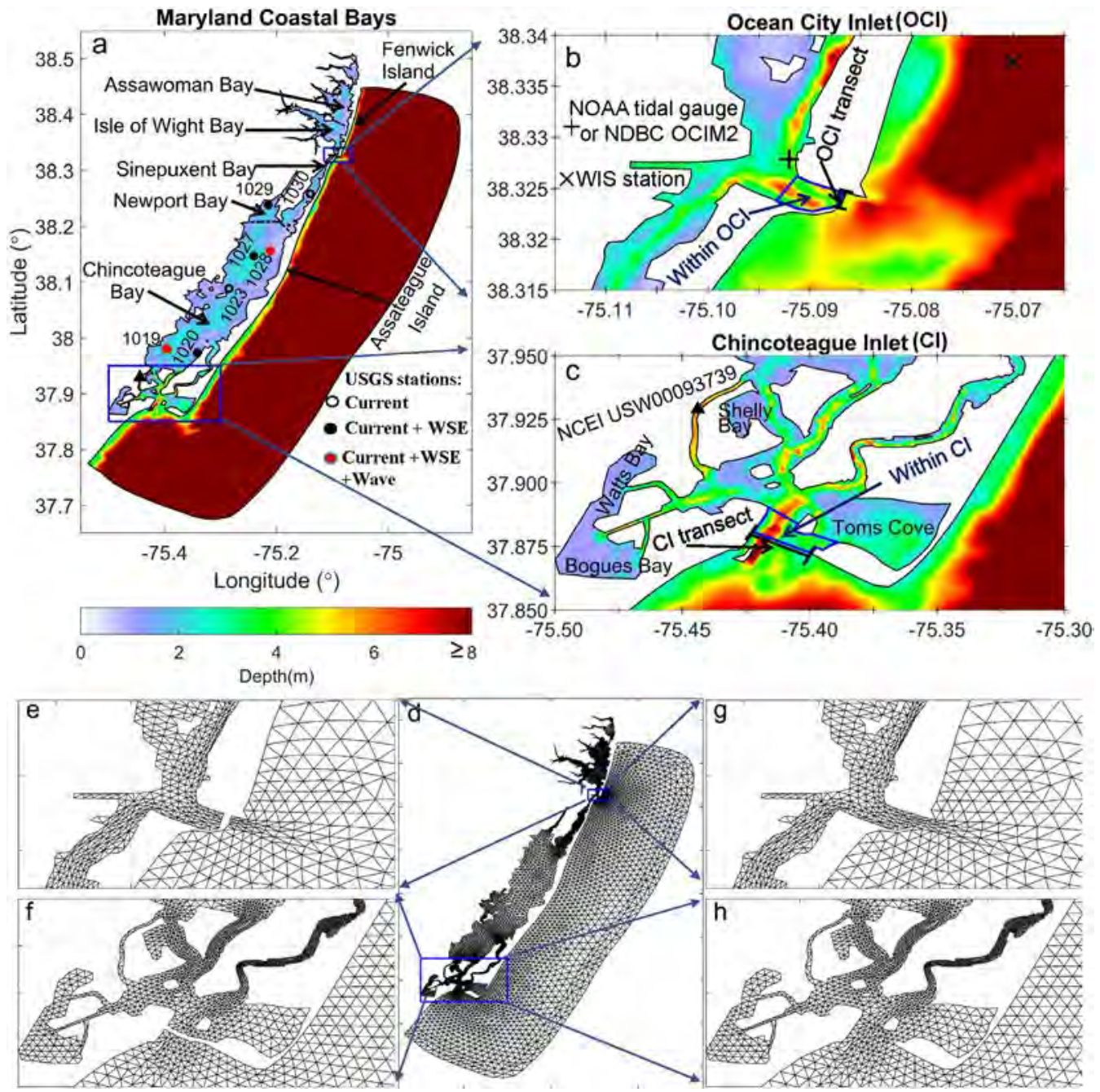

Fig. 1. (a) Bathymetry and geographic positions of five sub-bays and two islands in the MCBs, and enlarged views near the (b) OCI and (c) CI; unstructured grids of (d) the MCBs, closed (e) the OCI and (f) CI, and opened (g) the OCI and (h) CI.

$\left\{\begin{array}{l}S_{x x}=E\left[\frac{C_{g}}{C}\left(\cos ^{2} \theta_{w}+1\right)-\frac{1}{2}\right]+\frac{k_{x} k_{x}}{k^{2}} \frac{C^{2}}{L} A_{R} \\ S_{y y}=E\left[\frac{C_{g}}{C}\left(\sin ^{2} \theta_{w}+1\right)-\frac{1}{2}\right]+\frac{k_{y} k_{y}}{k^{2}} \frac{C^{2}}{L} A_{R}, \\ S_{x y}=E \frac{C_{g}}{C} \cos \theta_{w} \sin \theta_{w}+\frac{k_{x} k_{y}}{k^{2}} \frac{C^{2}}{L} A_{R}\end{array}\right.$

$E=\frac{1}{16} g H_{s}^{2}$,

where $\left(S_{x x}, S_{y y}\right)$ represents the 2D, vertically integrated radiation stress in the $(x, y)$ plane, and $S_{x y}$ is the $x$ or $y$ component across the $y$ or $x$ plane; $E, H_{s}, L$, and $\theta_{w}$ are wave energy, significant wave height, mean wave length, and mean wave direction; $C_{g}$ and $C$ are the group velocity and phase speed of the waves. The wave roller area $A_{R}$ is determined by the formulation of Svendsen (1984):

$A_{R}=\frac{\alpha}{\sqrt{2}} H_{s} L Q_{b}$,

where $\alpha$ is a parameter with a value of 0.06 and $Q_{b}$ is the fraction of breaking waves.

Mellor (2005) extended the 2D radiation stress formulation to a newly developed, 3D, depth-dependent version, which was subsequently incorporated into the 3D FVCOM/SWAVE system (Chen et al., 2013). The updated formulation of Mellor (2015) was adopted in the current study. It corrected an error related to the treatment of wave pressure and avoided the surface concentrated delta function, which are given as follows:

$S_{x x}=k E\left(\frac{k_{x} k_{x}}{k^{2}} F_{C C} F_{C S}-F_{S S} F_{S C}\right)+\frac{E}{2 D} \Im(\varsigma)+\frac{k_{x} k_{x}}{k^{2}} \frac{C^{2}}{L} A_{R} R_{z}$

$S_{y y}=k E\left(\frac{k_{y} k_{y}}{k^{2}} F_{C C} F_{C S}-F_{S S} F_{S C}\right)+\frac{E}{2 D} \Im(\varsigma)+\frac{k_{y} k_{y}}{k^{2}} \frac{C^{2}}{L} A_{R} R_{z}$

$S_{x y}=\frac{k_{x} k_{y}}{k^{2}} F_{C C} F_{C S}+\frac{k_{x} k_{y}}{k^{2}} \frac{C^{2}}{L} A_{R} R_{z}$,

$\Im(\varsigma)=\frac{\partial}{\partial \varsigma}\left(2 F_{C C} F_{S S}-F_{S S}^{2}\right)$,

$\left\{\begin{array}{l}F_{S S}=\frac{\sinh k D(1+\varsigma)}{\sinh k D} \\ F_{S C}=\frac{\sinh k D(1+\varsigma)}{\cosh k D} \\ F_{C S}=\frac{\cosh k D(1+\varsigma)}{\sinh k D} \\ F_{C C}=\frac{\cosh k D(1+\varsigma)}{\cosh k D}\end{array}\right.$

$D, E$, and $k$ are the water depth, wave energy, and wave number; $k_{x}$, and $k_{y}$ are the wave number components in the $x$ and $y$ directions, respectively; the value of sigma $\varsigma=\frac{z-\hat{\eta}}{D}$ varies from -1 to 0 with a 
corresponding $z$ from $-h$ to $\hat{\eta}$ (i.e., bottom to surface), and its integration $\int_{-1}^{0} \Im d \varsigma=1$. For deep water $(k D>5), \quad F_{S S}=F_{S C}$ $=F_{C S}=F_{C C}=e^{k D \varsigma}$. The vertical distribution function $R_{z}$ in the 3D surface boundary-layer roller term is expressed as (Svendsen et al., 2002; Warner et al., 2008):

$R_{z}=1-\tanh \left(\frac{2 \varsigma}{\gamma}\right)^{4}$

in which $R_{z}$ decays exponentially with the increasing water depth from surface to bottom, and $\gamma$ is the ratio of significant wave height to water depth $\left(\gamma=H_{s} / D\right)$.

The computations of current- and wave-induced bottom frictional stresses $\left[\left(\tau_{c x}, \tau_{c y}\right)\right.$ and $\left.\left(\tau_{w x}, \tau_{w y}\right)\right]$ in the wave-current coupled system adopt the wave-current boundary model of Madsen (1994):

$\left\{\begin{array}{c}\left(\tau_{c x}, \tau_{c y}\right)=\rho C_{d}\left(u_{c}, v_{c}\right) \sqrt{u_{c}^{2}+v_{c}^{2}} \\ C_{d}=\max \left[\frac{k^{2}}{\ln \left(\frac{z_{a b}}{z_{0 b}}\right)^{2}}, 0.0025\right]\end{array}\right.$

$\left(\tau_{w x}, \tau_{w y}\right)=0.5 \cdot f_{w}\left(u_{w}, v_{w}\right) \sqrt{u_{w}^{2}+v_{w}^{2}}$,

$f_{w}\left\{\begin{array}{lc}0.3 & \frac{C_{\mu} u_{b r}}{k_{N} \omega_{r}} \leq 0.2 \\ C_{\mu} e^{\left[.02\left(\frac{C_{\mu} u_{b r}}{k_{N} \omega_{r}}\right)^{-0.078}-8.82\right]} & 0.2<\frac{C_{\mu} u_{b r}}{k_{N} \omega_{r}}<10^{2}, \\ C_{\mu} e^{\left[5.61\left(\frac{C_{\mu} u_{b r}}{k_{N} \omega_{r}}\right)^{-0.109}-7.3\right]} & \frac{C_{\mu} u_{b r}}{k_{N} \omega_{r}} \geq 10^{2}\end{array}\right.$

$C_{\mu}=\left(1+2 \mu\left|\cos \phi_{c w}\right|+\mu^{2}\right)^{1 / 2}$

in which $\left(u_{c}, v_{c}\right)$ is the depth-averaged (near bottom) current velocity of the 2D (3D) model in $(x, y)$ space. The bottom drag coefficient $C_{d}$ is determined by logarithmically matching a bottom layer at a height of $z_{a b}$ with a von Kármán constant $k=0.41$; bottom roughness length $z_{0 b}$ and the corresponding Nikuradse roughness $k_{N}=30 \cdot z_{0 b}$ are set at 0.0017 and $0.05 \mathrm{~m}$, respectively. $\left(u_{w}, v_{w}\right)$ and $\omega_{r}$ stand for the near bottom wave orbital velocity $u_{b r}$ in the $(x, y)$ space and radian frequency; $f_{w}$ is the wave friction factor dependent upon the relative roughness $\left(\frac{C_{\mu} u_{b r}}{k_{N} \omega_{r}}\right) ; \phi_{c w}$ indicates the angle between the current and wave direction. Because the ratio $(\mu)$ of the bottom shear stress between current and wave is much smaller than 1 , the value of $C_{\mu}$ is set at 1 .

Combined wave-averaged stress $\left(\tau_{c w}\right)$ in the current direction was parameterized by Soulsby (1997):

$\tau_{c w}=\tau_{c}\left[1+1.2\left(\frac{\tau_{w}}{\tau_{c}+\tau_{w}}\right)^{3.2}\right]$

where $\tau_{c}$ and $\tau_{w}$ are the current- and wave-induced bottom frictional stresses.

Wind drag coefficient $C_{c D}$ in the circulation-only model is determined by the wind speed at a $10 \mathrm{~m}$ height $U_{10}$ with a piecewise linear polynomial (Large and Pond, 1981), whereas $C_{w c D}$ in the coupled system is a function of sea surface roughness $z_{0 s}$ (Donelan et al., 1993):

$C_{c D}=\left\{\begin{array}{l}1.2 \times 10^{-3} U_{10}<11 \mathrm{~m} / \mathrm{s} \\ \left(0.49+0.065 \times U_{10}\right) \times 10^{-3} 11 \mathrm{~m} / \mathrm{s} \leq U_{10} \leq 25 \mathrm{~m} / \mathrm{s}, \\ 2.115 \times 10^{-3} U_{10}>25 \mathrm{~m} / \mathrm{s}\end{array}\right.$

$z_{0 s}\left\{\begin{array}{c}3.7 \times 10^{-5} \cdot \frac{U_{10}^{2}}{g}\left(\frac{U_{10}}{C_{p}}\right)^{0.9} \frac{U_{10}}{C_{p}}<10 \\ 3.7 \times 10^{-5} \cdot \frac{U_{10}^{2}}{g} 10^{0.9} \frac{U_{10}}{C_{p}} \geq 10\end{array}\right.$,
$C_{w c D}=\left[\frac{\kappa}{\ln \left(\frac{10}{z_{0 s}}\right)}\right]^{2}$.

$z_{0 s}$ is related to inverse wave age $\frac{U_{10}}{C_{p}}$, in which $C_{p}$ is the wave phase speed. $k$ is a von Kármán constant at 0.41 . To avoid the unrealistic representation of the surface stress under strong wind conditions, an upper boundary of $z_{0 s}$ is set at 0.002 (Ardhuin et al., 2008).

In the wave-current coupled system, surface wave model (SWAVE; Qi et al., 2009) is based on the wave action density spectrum balance equation (Booij et al., 1999; SWAN Group, 2012):

$\frac{\partial N}{\partial t}+\nabla_{\vec{x}} \cdot\left[\left(\vec{c}_{g}+\vec{u}\right) N\right]+\frac{\partial C_{\sigma} N}{\partial \sigma}+\frac{\partial C_{\theta} N}{\partial \theta}=\frac{S_{t o t}}{\sigma}$,

where the propagation velocities in spectral space are defined as (Whitham, 1974; Phillips, 1977; Mei, 1983; Dietrich et al., 2013):

$\left\{\begin{array}{l}c_{\sigma}=\frac{\partial \sigma}{\partial H}\left(\frac{\partial H}{\partial t}+\vec{u} \cdot \nabla_{\vec{x}} H\right)-c_{g} \vec{k} \cdot \frac{\partial \vec{u}}{\partial s} \\ c_{\theta}=-\frac{1}{|\vec{k}|}\left(\frac{\partial \sigma}{\partial H} \frac{\partial H}{\partial m}+\vec{k} \cdot \frac{\partial \vec{u}}{\partial m}\right)\end{array}\right.$

Herein, $N$ is the wave action spectral density; $t$ is time; $\vec{c}_{g}$ and $\vec{u}$ are the wave group and ambient current velocity vectors in the $(x, y)$ plane; the quantities $C_{\sigma}$ and , $C_{\theta}$ are propagation velocities in spectral space $(\sigma, \theta) ; H$ denotes the water depth that includes the static bathymetry and variation of the water surface elevation; $\vec{k}=(|\vec{k}| \cos \theta,|\vec{k}| \sin \theta)$ is the wave number vector; $(s, m)$ is the coordinate parallel with and perpendicular to the wave direction $\theta$. Variations of wave action energy in the temporal, spatial, and spectral space are balanced by the energy source and sink in the $S_{\text {tot }}$ term. It includes wind input and whitecapping (Komen et al., 1984), bottom friction (Madsen, 1994), depthinduced wave breaking (Battjes and Janssen, 1978), and nonlinear wave-wave interactions. The maximum possible wave height $H_{\max }$ for a given water depth $H$ is determined by a breaker index $\gamma_{B J}$ via the expression $H_{\max }=\gamma_{B J} \times D$ in the bore-based breaking model. In the wave-current coupled model, depth-induced wave breaking is computed with the inclusion of water depth variation.

\subsection{Model inputs and observations}

The settings of the hydrodynamic model are similar to those of Kang et al. (2017). The hourly water surface elevations along the open boundary was interpolated from the National Oceanic and Atmospheric Administration's (NOAA) tide gauges (http://tidesandcurrents.noaa. gov) at Ocean City, Maryland $\left(38.328^{\circ} \mathrm{N}, 75.091^{\circ} \mathrm{W}\right)$ and Wachapreague, Virginia $\left(37.608^{\circ} \mathrm{N}, 75.686^{\circ} \mathrm{W}\right)$. Wave parameters (e.g., significant wave height, peak wave period, and mean wave direction) nested along the open boundary in 2011 and 2014 were derived from the $0.09^{\circ} \times 0.09^{\circ}$ gridded wave information studies (WIS) Wave Model (WISWAVE; Hubertz, 1992). Hindcasted wave information for the U.S. Atlantic East Coast is maintained by the U.S. Army Corps of Engineers' WIS (http://wis.usace.army.mil/hindcasts.html?dmn= atlantic). Temperature and salinity along the open boundary were interpolated from the 3-km, three-hourly outputs of the global Navy Coastal Ocean Model (https://www.ncdc.noaa.gov/data-access/modeldata/model-datasets/navoceano-ncom-reg). In order to examine the resolving ability of the wind fields under hurricane conditions, wind speeds from two favored data sources adopted by recent studies in the MCBs (Kang et al., 2017; Beudin et al., 2017) were compared against observational data from two stations. They are near the Ocean City Inlet at the National Data Buoy Center's (NDBC) OCIM2 (http://www.ndbc. noaa.gov) and Chincoteague Inlet at the National Centers for 
Environmental Information's (NCEI) USW00093739 (https://www. ncdc.noaa.gov). The aforementioned sources of wind fields include the $32-\mathrm{km}$, three-hourly product from the National Centers for Environmental Prediction's North American Regional Reanalysis (NARR, www.esrl.noaa.gov/psd/data/narr), and the 12-km, six-hourly data from the North American Mesoscale Model (NAM; https://www.ncdc. noaa.gov/data-access/model-data/model-datasets/north-americanmesoscale-forecast-system-nam). Atmospheric variables retrieved from the NARR model include wind speed, air pressure and temperature, relative humidity, downward shortwave and longwave, and upward longwave radiation fluxes. River flow and groundwater discharge from the adjacent watershed are ignored, assuming that they have limited effects on the inlet wave-current dynamics. The hourly water surface elevation and wave data near the Ocean City Inlet (Fig. 1a-b) downloaded from the NOAA tide gauge 8570283 (https://tidesandcurrents. noaa.gov/stationhome.html?id = 8570283) and WIS (http://wis.usace. army.mil) were used for model calibration (August 15-September 16, 2011) and validation (August 16-October 15, 2014). Additional water surface elevation, current velocity, and wave data in 2014 were obtained from the United States Geological Survey (USGS) Oceanographic Time-Series Measurement Database (https://woodshole.er.usgs.gov). The observational stations cover the Chincoteague Bay (CB1019, 1020, 1023, 1027, and 1028), Newport Bay (CB1029), and Sinepuxent Bay (CB1030). Details of the location and water depth of the observational stations are presented in Table 3.

\subsection{Design of numerical experiments}

The Maryland Department of Natural Resources (2011) reported that Hurricane Irene (2011) adversely impacted the habitat and living resources of the MCBs under strong wave-current conditions. Fig. 2a-b show the "best track" (i.e., temporal evolution of the low pressure center at a $10 \mathrm{~m}$ height) of Hurricane Irene (2011) along the U.S. East Coast and MCBs. The best track and bathymetry data were retrieved from the National Hurricane Center (http://www.nhc.noaa.gov) and the National Geophysical Data Center (https://www.ngdc.noaa.gov/ $\mathrm{mgg} / \mathrm{global} / \mathrm{etopo}$.html). Irene initiated on the east of the Lesser Antilles at GMT 21:00 on August 21, and continued to move northward along the U.S. East Coast and passed over the MCBs on August 28. Hurricane winds reached category 3 on the Saffir-Simpson Hurricane Wind Scale across the northern Caribbean Sea (Avila and Cangialosi, 2011).

Given the overall shallowness of the MCBs, calibration experiments mainly focused on the parameterizations of breaker index, bottom roughness length, and physical roughness length against the observed water surface elevation and wave parameters from August 15 to September 16, 2011 (Table 1). Additional runs (Table 2) were carried out to investigate the wind-wave-current dynamics and interactions. The calibrated model (Case CW1) was validated with additional observations of water surface elevation, current velocity, wave parameters from August 16 to October 15, 2014, which covered four major hurricanes in the Atlantic basin (https://en.wikipedia.org/wiki/2014 Atlantic_hurricane_season). Effects of local winds (Case CW2), wave-current interactions (Case C1/W1), and inlet closure (Cases CW3/CW4) on inlet dynamics were investigated by individually turning off each term relative to the baseline run (Case CW1). Individual wave effects on inlet circulation were analyzed by considering the wave-induced circulation by $3 \mathrm{D}$ radiation stress, bottom friction, and sea surface roughness (Cases CW5-CW7). In order to compare the wind-induced currents and waves with and without wave-current interactions, the circulation/wave-only model was run without local winds (Case C2/ W2). Wave-current interactions in a hypothetical single-inlet system of the MCBs were examined by artificially closing the OCI or $\mathrm{CI}$ in the uncoupled model (Cases $\mathrm{C} 3 / \mathrm{W} 3$ and $\mathrm{C} 4 / \mathrm{W} 4$ ). To determine the necessity of applying the 3D fully coupled model for inlet circulation, additional cases using the $2 \mathrm{D}$ radiation stress in the $3 \mathrm{D}$ and $2 \mathrm{D}$ wave-current coupled models (Cases CW8 and CW9) were also included. During the 1st maximum ebb, flood, and 2nd maximum ebb (GMT $16: 0008 / 27,00: 00$ and 18:00 08/28), spatial distributions of wave and current fields were presented. Calculation of the depth-integrated water transport flux (DWTF) across the inlet (Table 4) is expressed as follows:

$D W T F=\int_{-h}^{\eta} \int_{x_{1}}^{x_{2}} \vec{v}(x, z) \cdot \hat{n} d x d z$,

where $d x$ is the element width along the transect in $\mathrm{x}$ direction, and $d z$ is the element height (i.e., intra-sigma levels) along the vertical $z$ direction; $\vec{v}(x, z)$ is the current vector in this element and $\hat{n}$ is the unit vector normal to the projected transect. The integration is taken across the inlet $\left(x_{1}\right.$ to $\left.x_{2}\right)$ and throughout the water column from bottom to surface $(-h$ to $\eta)$. DWTF is defined as positive (negative) when the water flux is transported from (to) the adjacent Atlantic Ocean into (from) MCBs.

\subsection{Skill metrics}

Model performance was evaluated using the Pearson correlation coefficient $(C C)$, root-mean-square deviation (RMSD), relative bias $(R B)$, Brier skill score (BSS; Brier, 1950), and Willmott skill (WS; Willmott, 1981). Model-to-model comparison was quantified by the value of the absolute percentage difference (APD). Mathematical expressions of the abovementioned formulas are as follows:

$C C=\frac{\frac{1}{N} \sum_{n=1}^{N}\left(M_{o d}-\overline{M o d}\right)\left(O b s_{n}-\overline{O b s}\right)}{\sigma_{M o d_{n}} \sigma_{O b s_{n}}}$,

$R M S D=\left[\frac{1}{N} \sum_{n=1}^{N}\left(\operatorname{Mod}_{n}-O b s_{n}\right)^{2}\right]^{1 / 2}$,

$R B=\frac{\sum_{n=1}^{N}\left(\operatorname{Mod}_{n}-O b s_{n}\right)}{\sum_{n=1}^{N}\left|O b s_{n}\right|}$,

$B S S=1-\frac{\frac{1}{N} \sum_{n=1}^{N}\left(\operatorname{Mod}_{n}-O b s_{n}\right)^{2}}{\frac{1}{N} \sum_{n=1}^{N}\left(O b s_{n}-\overline{O b s}\right)^{2}}$,

$W S=1-\frac{\frac{1}{N} \sum_{n=1}^{N}\left(\operatorname{Mod}_{n}-O b s_{n}\right)^{2}}{\frac{1}{N} \sum_{n=1}^{N}\left(\left|\operatorname{Mod}_{n}-\overline{O b s}\right|+\left|O b s_{n}-\overline{O b s}\right|\right)^{2}}$,

$A P D=\frac{\operatorname{abs}\left(\sum_{n=1}^{N}\left(\operatorname{Mod}_{n}-\text { Base }_{n}\right)\right)}{\sum_{n=1}^{N} \mid \text { Base }_{n} \mid}$,

in which $\overline{O b s}$ and $\overline{M o d e l}$ are the averaged values of the observation $O b s_{n}$ and simulation $\operatorname{Mod}_{n}$ in a sample of size $N ; \sigma_{M_{0 d}}$ and $\sigma_{O b s_{n}}$ represent the corresponding standard deviations; Base $_{n}$ denotes the value calculated from the baseline run. $C C$ and $R B$ measure the linear correlation and the relative difference between the observed and modeled values, respectively; RMSD is used for a direct model-to-data comparison. BSS is a skill index less than 1; a positive value means that simulation is better than the prediction using the time-averaged mean. WS determines the level of model skill, in which poor, good, very good, excellent, and perfect are represented by $0-0.3,0.3-0.6,0.6-0.8,0.8-1$, and 1 , respectively.

\section{Model skill assessment and wave-current simulations}

\subsection{Calibration and validation of the wave-current coupled model}

Because wind forcing is the primary agent that generates ocean currents and surface waves, the quality of the modeled winds from the 

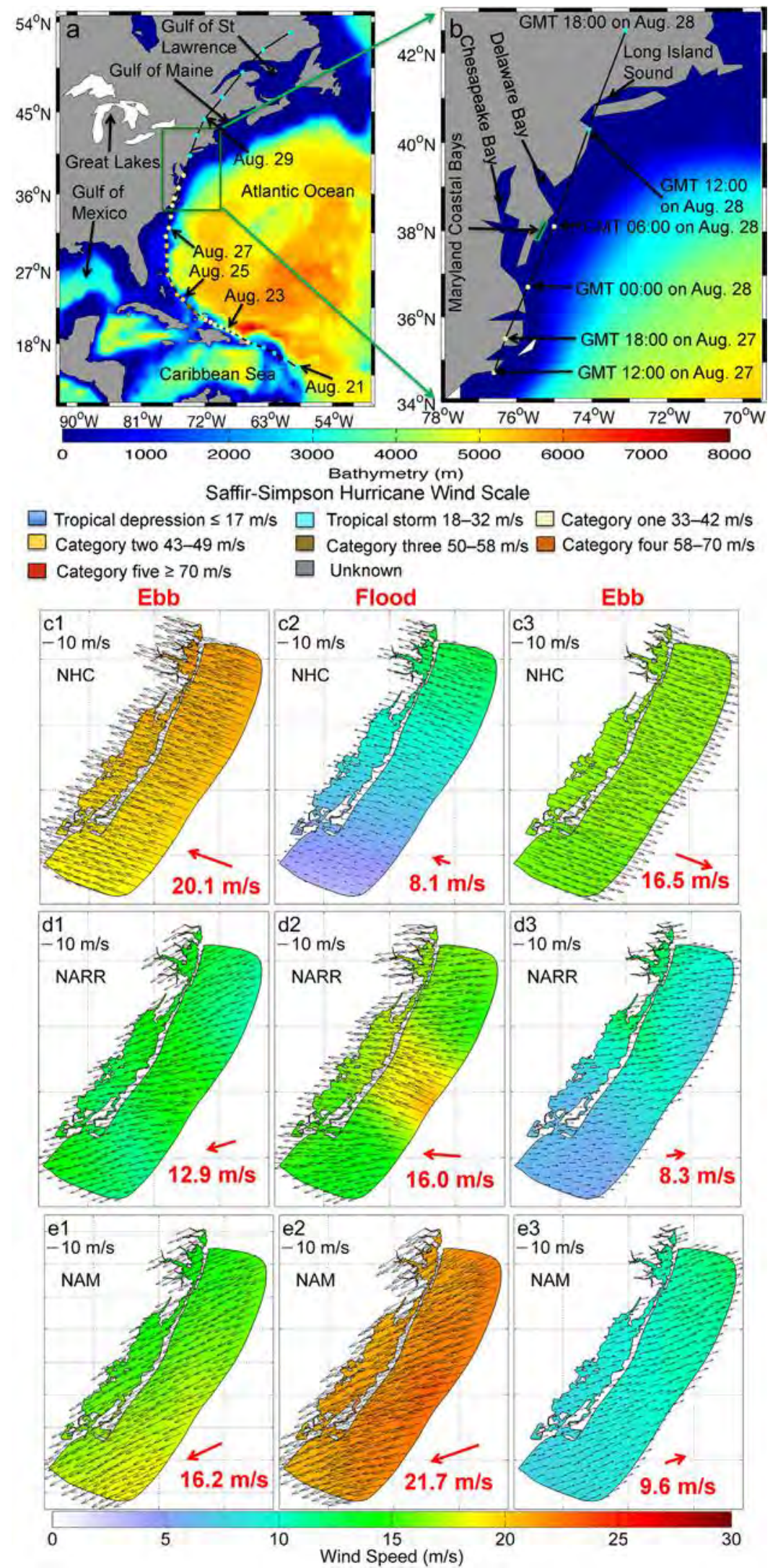

Fig. 2. The "best track" of Hurricane Irene from August 21 to 30, 2011 along the (a) Central America and U.S. East Coast and (b) near the MCBs, and spatial distributions of wind fields from the (c1-3) NHC, (d1-3) NARR, and (e1-3) NAM during Hurricane Irene. Red arrows in (c1-3, d1-3, and e1-3) indicate the spatially averaged wind speeds. (For interpretation of the references to color in this figure legend, the reader is referred to the web version of this article.) 
Table 1

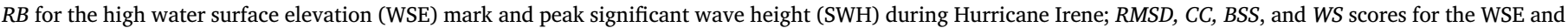
SWH from August 15 to September 16, 2011.

\begin{tabular}{|c|c|c|c|c|c|c|c|c|c|c|c|c|c|}
\hline \multirow[t]{2}{*}{ Case } & \multirow{2}{*}{$\begin{array}{l}\text { Breaking index } \\
\gamma_{B J}\end{array}$} & \multirow{2}{*}{$\begin{array}{l}\text { Physical length of bottom } \\
\text { roughness } k_{N}(\mathrm{~m})\end{array}$} & \multirow{2}{*}{$\begin{array}{l}\text { Bottom roughness } \\
\text { length } z_{0 b}(\mathrm{~m})\end{array}$} & \multicolumn{2}{|l|}{$R B$} & \multicolumn{2}{|c|}{$R M S D(\mathrm{~m})$} & \multicolumn{2}{|l|}{$C C$} & \multicolumn{2}{|l|}{ BSS } & \multicolumn{2}{|l|}{ WS } \\
\hline & & & & HighWSE mark & Peak SWH & WSE & SWH & WSE & SWH & WSE & SWH & WSE & SWH \\
\hline $\mathrm{A} 1$ & 0.73 & 0.05 & 0.0017 & $-11 \%$ & $-10 \%$ & 0.12 & 0.22 & 0.92 & 0.92 & 0.76 & 0.81 & 0.92 & 0.95 \\
\hline A2 & 0.30 & 0.05 & 0.0017 & $-11 \%$ & $-60 \%$ & 0.12 & 0.35 & 0.92 & 0.77 & 0.76 & 0.52 & 0.92 & 0.77 \\
\hline A3 & 0.90 & 0.05 & 0.0017 & $-10 \%$ & $-2 \%$ & 0.12 & 0.22 & 0.92 & 0.93 & 0.76 & 0.81 & 0.92 & 0.96 \\
\hline A4 & 0.90 & 0.03 & 0.0010 & $-15 \%$ & $6 \%$ & 0.12 & 0.30 & 0.91 & 0.9 & 0.75 & 0.64 & 0.92 & 0.93 \\
\hline A5 & 0.90 & 0.11 & 0.0036 & $-9 \%$ & $-22 \%$ & 0.11 & 0.22 & 0.93 & 0.93 & 0.78 & 0.81 & 0.93 & 0.94 \\
\hline
\end{tabular}

Table 2

Numerical experiments for analyzing wave-current dynamics and interactions during Hurricane Irene.

\begin{tabular}{|c|c|c|c|c|}
\hline Case & Model & Wave-current interactions & Local winds & Inlet treatment \\
\hline $\mathrm{C} 1$ & 3D FVCOM & Off & On & Both inlets are open \\
\hline $\mathrm{C} 2$ & 3D FVCOM & Off & Off & Both inlets are open \\
\hline C3 & 3D FVCOM & Off & On & OCI is closed \\
\hline C4 & 3D FVCOM & Off & On & $\mathrm{CI}$ is closed \\
\hline W1 & SWAVE & Off & On & Both inlets are open \\
\hline W2 & SWAVE & Off & Off & Both inlets are open \\
\hline W3 & SWAVE & Off & On & $\mathrm{OCI}$ is closed \\
\hline W4 & SWAVE & Off & On & $\mathrm{CI}$ is closed \\
\hline CW1 & 3D FVCOM/SWAVE & Fully coupled & On & Both inlets are open \\
\hline CW2 & 3D FVCOM/SWAVE & Fully coupled & Off & Both inlets are open \\
\hline CW3 & 3D FVCOM/SWAVE & Fully coupled & On & OCI is closed \\
\hline CW4 & 3D FVCOM/SWAVE & Fully coupled & On & $\mathrm{CI}$ is closed \\
\hline CW5 & 3D FVCOM/SWAVE & $3 \mathrm{D}$ radiation stress & On & Both inlets are open \\
\hline CW6 & 3D FVCOM/SWAVE & Wave-induced bottom friction & On & Both inlets are open \\
\hline CW7 & 3D FVCOM/SWAVE & Wave-induced sea surface roughness & On & Both inlets are open \\
\hline CW8 & 3D FVCOM/SWAVE & Fully coupled with $2 \mathrm{D}$ radiation stress & On & Both inlets are open \\
\hline CW9 & 2D FVCOM/SWAVE & Fully coupled with $2 \mathrm{D}$ radiation stress & On & Both inlets are open \\
\hline
\end{tabular}

NARR and NAM was examined (Fig. 3a-c). Although wind speed produced from the NAM successfully captured the temporal variations of the observed values near the OCI and CI $(C C=0.74$ and 0.85, $B S S=0.42$ and 0.56 , and $W S=0.85$ and 0.91 ), slightly stronger scores were obtained from the NARR wind model $(C C=0.76$ and 0.85 , $B S S=0.51$ and 0.70 , and $W S=0.86$ and 0.92 ). During Hurricane Irene, the maximum wind speed $(16.3 \mathrm{~m} / \mathrm{s})$ observed at OCI station was marginally overestimated by $1.2 \mathrm{~m} / \mathrm{s}(7 \%)$ from the NARR. However, this error increased to $4.9 \mathrm{~m} / \mathrm{s}(30 \%)$ from the NAM. By replacing the NAM with NARR, the $C C$ and WS for the wind direction near the OCI was improved from 0.46 to 0.53 and 0.72 to 0.75 , respectively. It can be concluded that the NARR wind model yielded a higher predictive skill in replicating the time series of the observational winds under hurricane conditions. In order to distinguish the quality of the NARR and NAM wind products in spatial scale, their wind fields were compared with the National Hurricane Center's (NHC) best track-based wind data during Hurricane Irene (Fig. 2c-e). The modified parametric model used to generate the NHC's hurricane winds was based on the maximum sustained wind speed at the storm center and the radius of maximum wind (Holland, 1980; Xia et al., 2008). Although moderate discrepancies in wind fields were observed between the atmospheric models (e.g., NARR and NAM) and NHC data, they all showed a similar spatial pattern (e.g., switching from easterly to westerly). On average, the wind direction predicted by the NAM deviated from that of the NHC by $41^{\circ}$, which was reduced to $25^{\circ}$ by the NARR. Because accurate predictions of hurricane track and wind field have been a challenging task for the current weather forecast models (e.g., the latest Advanced Research Weather Research and Forecasting Model, see Fig. 3 in Klausmann, 2014), the quality of the wind products from both atmospheric models compared in this study are satisfactory. Given that the
NARR wind model outperformed the NAM, especially during Hurricane Irene, it was selected to drive the wave-current model for further calibration and validation.

Model calibration focused on parameterizations of the breaker index $\gamma_{B J}$, physical roughness length $k_{N}$, and bottom roughness length $z_{0 b}$. All simulations (Table 1 ) yielded satisfactory statistics for the water surface elevation and significant wave height near the OCI, except for Case A2 $\left(\gamma_{B J}=0.3, k_{N}=0.05 \mathrm{~m}\right.$, and $\left.z_{0 b}=0.0017 \mathrm{~m}\right)$. During Hurricane Irene, Case A2 noticeably underestimated the extreme value of significant wave height $(3.58 \mathrm{~m})$ by $2.15 \mathrm{~m}(60 \%)$, resulting from an excessive breaking by reducing $\gamma_{B J}$ from the default setting at 0.73 (Case A1) to 0.3. In contrast, the enhancement of $\gamma_{B J}$ from 0.73 to 0.90 (Case A3) decreased the underestimation from $0.36 \mathrm{~m}(10 \%)$ to $0.08 \mathrm{~m}(2 \%)$. This result was consistent with that from van der Westhuysen (2010), which stated that an enhanced $\gamma_{B J}(0.8-0.95)$ was required to correct the systematically underestimated significant wave height. Based on the bore-based breaking model proposed by Battjes and Janssen (1978), the cumulative probability distribution of individual wave height follows the Rayleigh type and the truncated maximum wave height is determined by $H_{\max }=\gamma_{B J} \times D$, where $D$ is the local water depth. Therefore, the estimated significant wave height was enhanced when an increased $\gamma_{B J}$ was applied (i.e., allowing for a higher $H_{\max }$ at a given local water depth). It should be noted that $\gamma_{B J}$ has a wide range of limits, and its optimization depends on various site-specific conditions, such as surf zone or finite depth wave growth situations (van der Westhuysen, 2010; Xu et al., 2013). When $z_{0 b}$ and $k_{N}$ were decreased from $0.0017 \mathrm{~m}$ and $0.05 \mathrm{~m}$ (Case A3) to $0.001 \mathrm{~m}$ and $0.03 \mathrm{~m}$ (Case A4) respectively, the overall scores of the $R B, R M S D, C C, B S S$, and $W S$ for water surface elevation and significant wave height slightly worsened. Further enhancements of $z_{0 b}$ and $k_{N}$ from Case A3 to A5 $(0.0036 \mathrm{~m}$ and $0.11 \mathrm{~m})$ 


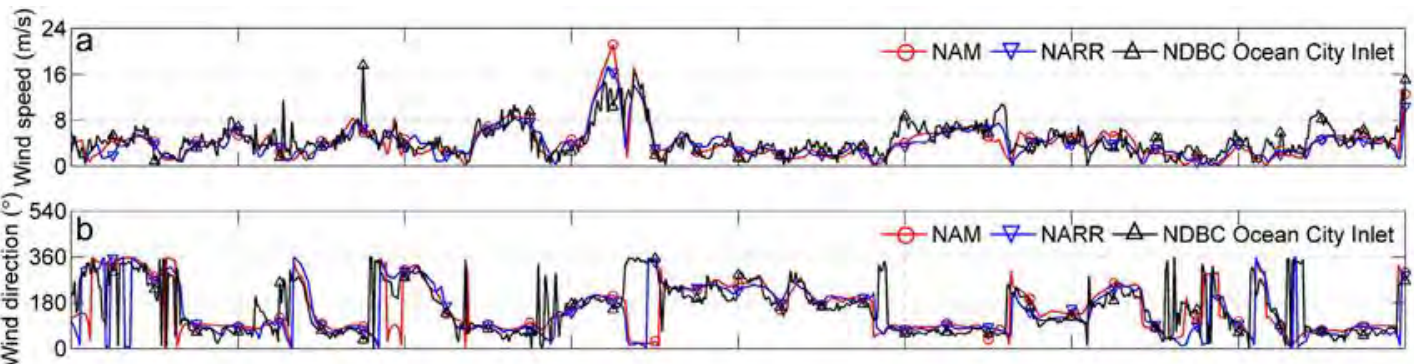

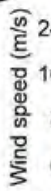

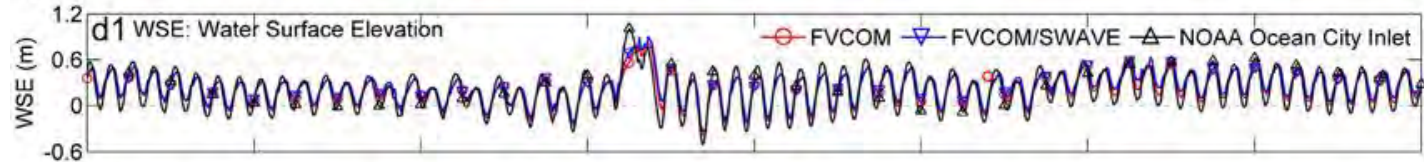
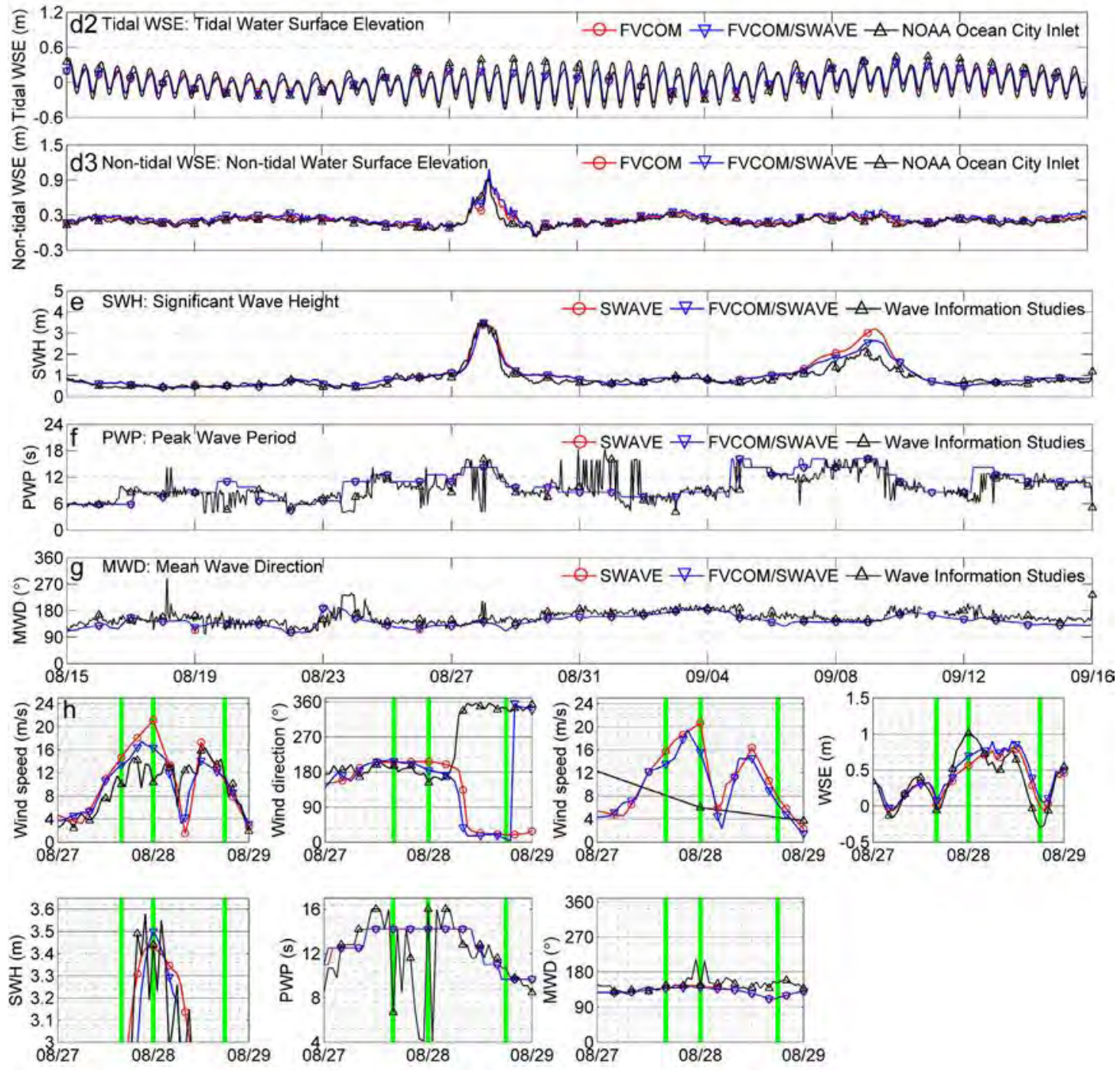

Date in 2011 (month/day)

Fig. 3. Time series of (a) and (c) wind speed and (b) direction from the NARR, NAM and observations near the OCI and CI; (d1/d2/d3) and (e)-(g) are water/tidal/ non-tidal surface elevations and wave parameters from simulations and observations near and outside the OCI; (h) shows the aforementioned variables from August 27 to 29,2011 , in which green bars indicate the moments at the 1st maximum ebb, flood, and 2nd maximum ebb during Hurricane Irene. (For interpretation of the references to color in this figure legend, the reader is referred to the web version of this article.) 
Table 3

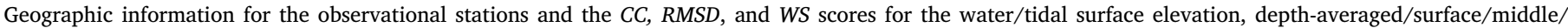

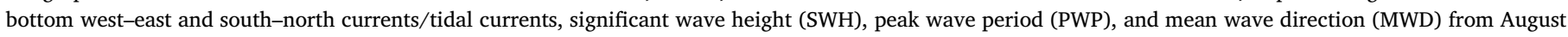
16 to October 15, 2014.

\begin{tabular}{|c|c|c|c|c|c|c|c|}
\hline Variable & Station & Long. & Lat. & Depth & CC & $R M S D$ & WS \\
\hline \multirow[t]{3}{*}{ Water/Tidal surface elevation } & NOAA & $-75.0917^{\circ}$ & $38.3283^{\circ}$ & $4.4 \mathrm{~m}$ & $0.91 / 0.95$ & $13 / 10 \mathrm{~cm}$ & $0.91 / 0.91$ \\
\hline & CB1019 & $-75.3961^{\circ}$ & $37.9813^{\circ}$ & $2.3 \mathrm{~m}$ & $0.93 / 0.90$ & $6 / 4 \mathrm{~cm}$ & $0.94 / 0.93$ \\
\hline & CB1028 & $-75.2116^{\circ}$ & $38.1585^{\circ}$ & $1.3 \mathrm{~m}$ & $0.84 / 0.98$ & $15 / 2 \mathrm{~cm}$ & $0.71 / 0.97$ \\
\hline \multirow{7}{*}{$\begin{array}{l}\text { West-east depth-averaged/ } \\
\text { surface/middle/bottom/ } \\
\text { currents/tidal current }\end{array}$} & CB1019 & $-75.3961^{\circ}$ & $37.9813^{\circ}$ & $2.3 \mathrm{~m}$ & $0.92 / 0.58 / 0.86 / 0.73 / 0.98$ & $4 / 10 / 6 / 7 / 3 \mathrm{~cm} / \mathrm{s}$ & $0.93 / 0.74 / 0.91 / 0.74 / 0.96$ \\
\hline & CB1020 & $-75.3445^{\circ}$ & $37.9748^{\circ}$ & $1.4 \mathrm{~m}$ & $0.70 / 0.66 / 0.65 / 0.57 / 0.78$ & $7 / 9 / 9 / 4 / 6 \mathrm{~cm} / \mathrm{s}$ & $0.62 / 0.55 / 0.50 / 0.63 / 0.64$ \\
\hline & CB1023 & $-75.2831^{\circ}$ & $38.0914^{\circ}$ & $1.9 \mathrm{~m}$ & $0.40 / 0.32 / 0.38 / 0.27 / 0.69$ & $5 / 8 / 6 / 4 / 3 \mathrm{~cm} / \mathrm{s}$ & $0.61 / 0.56 / 0.53 / 0.56 / 0.60$ \\
\hline & CB1027 & $-75.2380^{\circ}$ & $38.1493^{\circ}$ & $2.2 \mathrm{~m}$ & $0.44 / 0.27 / 0.27 / 0.29 / 0.85$ & $3 / 4 / 4 / 4 / 1 \mathrm{~cm} / \mathrm{s}$ & $0.66 / 0.55 / 0.54 / 0.54 / 0.91$ \\
\hline & CB1028 & $-75.2116^{\circ}$ & $38.1585^{\circ}$ & $1.3 \mathrm{~m}$ & $0.54 / 0.22 / 0.36 / 0.36 / 0.95$ & $12 / 15 / 15 / 8 / 11 \mathrm{~cm} / \mathrm{s}$ & $0.32 / 0.39 / 0.32 / 0.47 / 0.30$ \\
\hline & CB1029 & $-75.2142^{\circ}$ & $38.2395^{\circ}$ & $1.7 \mathrm{~m}$ & $0.44 / 0.37 / 0.12 .0 .13 / 0.94$ & $2 / 6 / 5 / 5 / 1 \mathrm{~cm} / \mathrm{s}$ & $0.60 / 0.54 / 0.44 / 0.43 / 0.89$ \\
\hline & CB1030 & $-75.1397^{\circ}$ & $38.2592^{\circ}$ & $1.9 \mathrm{~m}$ & $0.85 / 0.79 / 0.74 / 0.60 / 0.98$ & $5 / 7 / 7 / 8 / 0 \mathrm{~cm} / \mathrm{s}$ & $0.89 / 0.89 / 0.84 / 0.62 / 0.96$ \\
\hline \multirow{7}{*}{$\begin{array}{l}\text { South-north depth-averaged/ } \\
\text { surface/middle/bottom/ } \\
\text { currents/tidal current }\end{array}$} & CB1019 & $-75.3961^{\circ}$ & $37.9813^{\circ}$ & $2.3 \mathrm{~m}$ & $0.93 / 0.66 / 0.93 / 0.86 / 0.97$ & $7 / 17 / 7 / 10 / 6 \mathrm{~cm} / \mathrm{s}$ & $0.94 / 0.76 / 0.95 / 0.81 / 0.96$ \\
\hline & CB1020 & $-75.3445^{\circ}$ & $37.9748^{\circ}$ & $1.4 \mathrm{~m}$ & $0.85 / 0.82 / 0.82 / 0.82 / 0.90$ & $7 / 10 / 9 / 5 / 6 \mathrm{~cm} / \mathrm{s}$ & $0.90 / 0.86 / 0.84 / 0.90 / 0.92$ \\
\hline & CB1023 & $-75.2831^{\circ}$ & $38.0914^{\circ}$ & $1.9 \mathrm{~m}$ & $0.90 / 0.83 / 0.87 / 0.89 / 0.99$ & $6 / 10 / 8 / 7 / 2 \mathrm{~cm} / \mathrm{s}$ & $0.95 / 0.90 / 0.93 / 0.89 / 0.99$ \\
\hline & CB1027 & $-75.2380^{\circ}$ & $38.1493^{\circ}$ & $2.2 \mathrm{~m}$ & $0.71 / 0.66 / 0.67 / 0.50 / 0.97$ & $4 / 6 / 5 / 5 / 1 \mathrm{~cm} / \mathrm{s}$ & $0.82 / 0.79 / 0.80 / 0.68 / 0.99$ \\
\hline & CB1028 & $-75.2116^{\circ}$ & $38.1585^{\circ}$ & $1.3 \mathrm{~m}$ & $0.50 / 0.36 / 0.49 / 0.93 / 0.89$ & $7 / 11 / 9 / 7 / 0 \mathrm{~cm} / \mathrm{s}$ & $0.64 / 0.62 / 0.59 / 0.95 / 0.60$ \\
\hline & CB1029 & $-75.2142^{\circ}$ & $38.2395^{\circ}$ & $1.7 \mathrm{~m}$ & $0.65 / 0.36 / 0.53 / 0.20 / 0.94$ & $3 / 7 / 4 / 6 / 2 \mathrm{~cm} / \mathrm{s}$ & $0.74 / 0.56 / 0.69 / 0.49 / 0.84$ \\
\hline & CB1030 & $-75.1397^{\circ}$ & $38.2592^{\circ}$ & $1.9 \mathrm{~m}$ & $0.86 / 0.78 / 0.78 / 0.79 / 0.97$ & $8 / 12 / 11 / 11 / 4 \mathrm{~cm} / \mathrm{s}$ & $0.92 / 0.88 / 0.88 / 0.76 / 0.98$ \\
\hline \multirow[t]{6}{*}{ SWH } & CB1019 & $-75.3961^{\circ}$ & $37.9813^{\circ}$ & $2.3 \mathrm{~m}$ & 0.59 & $13 \mathrm{~cm}$ & 0.69 \\
\hline & CB1020 & $-75.3445^{\circ}$ & $37.9748^{\circ}$ & $1.4 \mathrm{~m}$ & 0.57 & $7 \mathrm{~cm}$ & 0.76 \\
\hline & CB1027 & $-75.2380^{\circ}$ & $38.1493^{\circ}$ & $2.2 \mathrm{~m}$ & 0.59 & $14 \mathrm{~cm}$ & 0.68 \\
\hline & CB1028 & $-75.2116^{\circ}$ & $38.1585^{\circ}$ & $1.3 \mathrm{~m}$ & 0.61 & $9 \mathrm{~cm}$ & 0.73 \\
\hline & CB1029 & $-75.2142^{\circ}$ & $38.2395^{\circ}$ & $1.7 \mathrm{~m}$ & 0.66 & $9 \mathrm{~cm}$ & 0.78 \\
\hline & WIS & $-75.0703^{\circ}$ & $38.3376^{\circ}$ & $11.1 \mathrm{~m}$ & 0.83 & $21 \mathrm{~cm}$ & 0.89 \\
\hline \multirow[t]{6}{*}{ PWP } & CB1019 & $-75.3961^{\circ}$ & $37.9813^{\circ}$ & $2.3 \mathrm{~m}$ & 0.17 & $0.68 \mathrm{~s}$ & 0.33 \\
\hline & CB1020 & $-75.3445^{\circ}$ & $37.9748^{\circ}$ & $1.4 \mathrm{~m}$ & 0.11 & $0.40 \mathrm{~s}$ & 0.17 \\
\hline & CB1027 & $-75.2380^{\circ}$ & $38.1493^{\circ}$ & $2.2 \mathrm{~m}$ & 0.22 & $0.54 \mathrm{~s}$ & 0.36 \\
\hline & CB1028 & $-75.2116^{\circ}$ & $38.1585^{\circ}$ & $1.3 \mathrm{~m}$ & 0.29 & $0.39 \mathrm{~s}$ & 0.50 \\
\hline & CB1029 & $-75.2142^{\circ}$ & $38.2395^{\circ}$ & $1.7 \mathrm{~m}$ & 0.30 & $0.44 \mathrm{~s}$ & 0.43 \\
\hline & WIS & $-75.0703^{\circ}$ & $38.3376^{\circ}$ & $11.1 \mathrm{~m}$ & 0.63 & $2.18 \mathrm{~s}$ & 0.78 \\
\hline MWD & WIS & $-75.0703^{\circ}$ & $38.3376^{\circ}$ & $11.1 \mathrm{~m}$ & 0.61 & $28.76^{\circ}$ & 0.78 \\
\hline
\end{tabular}

resulted in a greater underestimation of the peak significant wave height by $0.79 \mathrm{~m}(22 \%)$, presumably due to the increased $k_{N}$ (i.e., stronger wave dissipation from the bottom friction, see Madsen, 1994). Therefore, the tuning parameters from Case A3 $\left(\gamma_{B J}=0.9\right.$, $k_{N}=0.05 \mathrm{~m}$, and $z_{0 b}=0.0017 \mathrm{~m}$ ) were adopted for further discussion (Case CW1 in Table 2). As shown in Figs. $3 \mathrm{~d} 1$ and $3 \mathrm{e}-\mathrm{g}$, the wave-current coupled FVCOM/SWAVE model satisfactorily reproduced water surface elevation $(R M S D=0.12 \mathrm{~m}, \quad C C=0.92, W S=0.92$, and $B S S=0.76)$ and significant wave height $(R M S D=0.22 \mathrm{~m}, C C=0.93$, $W S=0.96$, and $B S S=0.81$ ). Statistical scores for the peak wave period and mean wave direction were also reasonable (e.g., RMSD of $2.71 \mathrm{~s}$ and $21^{\circ}$, and $C C$ of 0.6 and 0.7$)$. The observed extreme value of significant wave height in the wake of Tropical Storm Lee (September $8-10,2011)$ at $2.34 \mathrm{~m}$ was over-predicted by $0.28 \mathrm{~m}(12 \%)$ from the wave-current baseline run (Case CW1). Panchang et al. (2008) indicated that the grid resolution of WISWAVE in the Atlantic coast $(\sim 25 \mathrm{~km})$ was too coarse to resolve the intricate coastal dynamics in the Gulf of Maine $(0.5 \mathrm{~km})$. Therefore, model-to-data bias of the wave parameters at the coastal station WIS (Fig. 1b) likely resulted from inaccurate wave information nested along the open boundary of our coastal model (e.g., less than 2-km resolution).

With additional water surface elevation, current velocity, and wave data from August 16 to October 15, 2014, model performance was validated against observations from the NOAA tide gauge, WIS, Chincoteague Bay (CB1019, 1020, 1023, 1027, and 1028), Newport Bay (CB1029), and Sinepuxent Bay (CB1030), see Table 3 and Fig. 4. Overall, Case CW1 reproduced the observed water surface elevations reasonably well with $C C \geq 0.84, R M S D \leq 15 \mathrm{~cm}$, and $W S \geq 0.71$.
Given the damping effect caused by bottom friction in shallow regions, variation of the water surface elevation in the lower bays at stations CB1019 and 1028 was weaker than that at the NOAA tide gauge. Inaccurate representations of the complex bathymetry (Olabarrieta et al., 2011) and shallow-water processes (Chen et al., 2015; Salmon et al., 2015; Hopkins et al., 2016), in addition to the lack of consideration for the seagrass meadows (Beudin et al., 2017) are likely the culprits of the model-to-data bias. Overall, current velocity was well reproduced by our model with a reasonable WS (Table 3 ). The simulation from Ganju et al. (2017) yielded a reliable BSS (0.56) for the water surface elevation in the middle of Chincoteague Bay from November 1, 2014 to March 1, 2015. In the current study, the grand means of BSS at three available stations decreased to 0.26 , presumably due to the absence of bathymetric changes in the model. Because the main objective is to understand the wave-current dynamics and interactions near the deep inlet (BSS $=0.74$ at the nearby NOAA gauge) rather than the quantification of storm-induced bathymetric changes in the shallow Chincoteague Bay, our model performance is acceptable for this application. We further examined the model performance in simulating the tides and tidal currents over the study region (Fig. 4 and Table 3). On average, simulated tides and tidal currents agreed well with observed values (e.g., grand means of $W S$ at 0.94 and 0.82 , respectively). The only exception was the estimation of tidal current at the shallowest station, CB1028, which was located far away from both the OCI and CI. As mentioned above, inaccurate prediction of the shallow water process over this complex region without the consideration of the bathymetric change or the seagrass meadows was responsible for the relatively weaker model skill. At other shallow-water stations (e.g., depth 


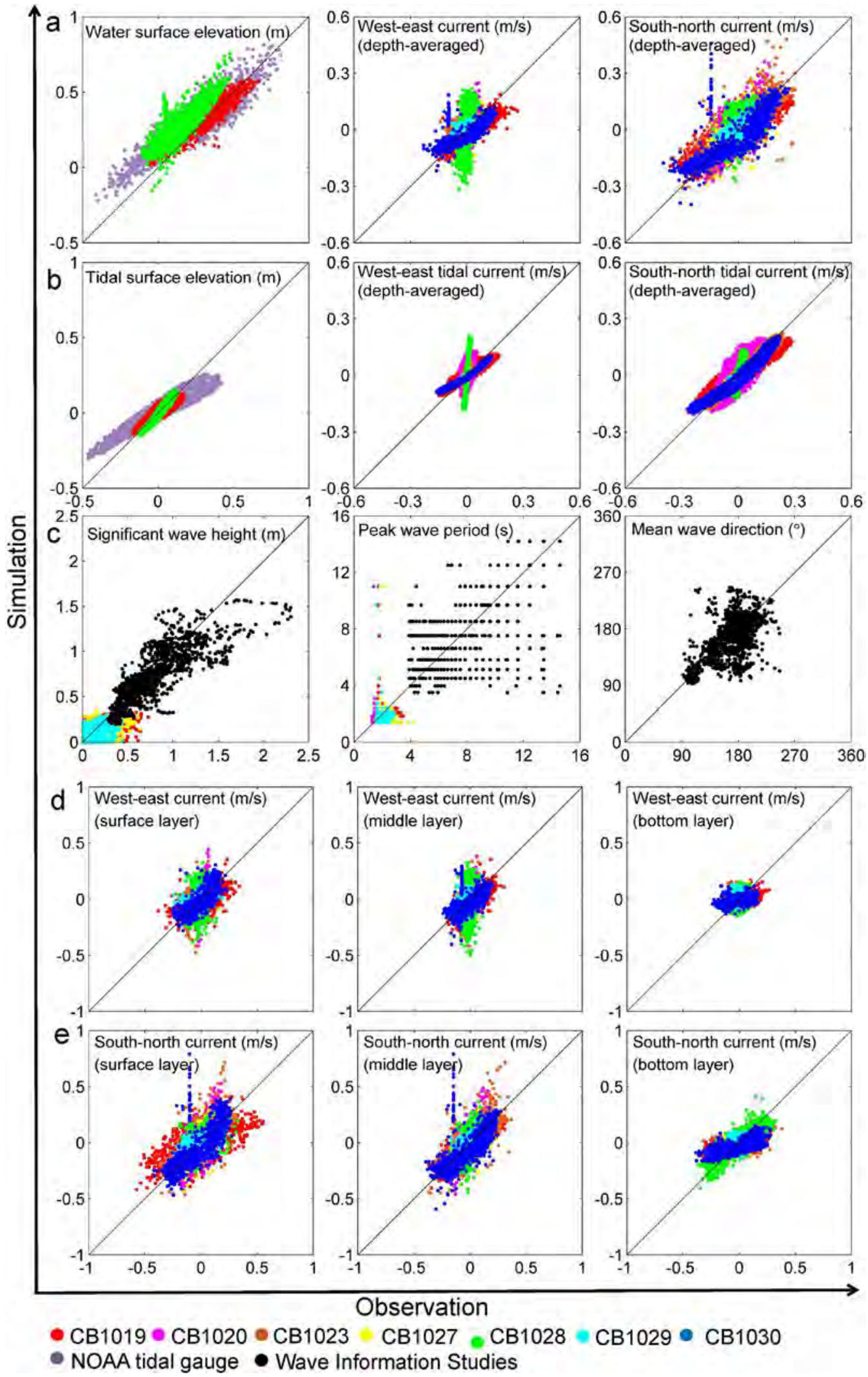

Fig. 4. Scatterplots of the simulated (a) water surface elevation and depth-averaged current velocity, (b) tidal surface elevation and depth-averaged tidal current, (c) wave parameters, and surface/middle/bottom currents in (d) west-east and (e) south-north directions versus observations for model validation from August 16 to October 15, 2014. 
between 1.4 and $2.3 \mathrm{~m}$ ), both the west-east and south-north tidal currents produced from the model scattered well around the line of perfect fit compared with observations. In addition to the 2D results, the numerical model successfully reproduced the 3D current velocity (e.g., stronger in the surface and middle layers while weaker in the bottom layer) with a very good WS (grand mean across all stations was 0.69). In addition, the current magnitude in the south-north direction was generally greater than the west-east component. Therefore, the circulation in the lagoon is mainly along the bay axis with relatively intense flow in the surface and middle layers. Although the circulation model without wave-current interactions produced comparable simulation results in the lagoon (not shown here), it was expected that the wave-induced currents likely to be significant near the inlet region during hurricane conditions (e.g., up to $1.5 \mathrm{~m} / \mathrm{s}$, see Section 4.2). Additional observations of 3D currents near the inlet and along the surf zone in the future can help verify our findings, as well as to provide new insight into wave-current dynamics.

Overall, the wave model successfully reproduced the significant wave height and mean wave direction over the study region, with a very good skill score (e.g., $W S \geq 0.68$ ). The significant wave height observed from WIS at $11.1 \mathrm{~m}$ water depth was significantly greater than that in the lagoon at depth $\leq 2.3 \mathrm{~m}$ (up to $2.3 \mathrm{~m}$ versus below $0.7 \mathrm{~m}$ ), where strong dissipation and breaking occurred. This complex shallowwater process in the lagoon also resulted in a lower level of model skill in simulating significant wave height relative to that at the coastal station (e.g., $C C$ of $0.57-0.66$ versus 0.83 and WS of $0.68-0.78$ versus 0.89). Compared with the significant wave height and mean wave direction, larger errors appeared in the scatterplot of the peak wave period (PWP). One possible explanation is that the simulated PWP in the wave model was discretized into discontinuous segments with a limited resolution (e.g., $\triangle \mathrm{PWP} / \mathrm{PWP}=0.14$ ). The scatter index (i.e., normalizing RMSD by the mean) for the PWP at the shallow-water stations in the MCBs $(27.2 \%$ versus $27.3 \%)$ was comparable to those reported by Dodet et al. (2013) behind the inlet of the Albufeira Lagoon (Portugal). The $C C$ for the PWP at WIS ( 0.63 versus 0.3 ) was better than that indicated by Qi et al. (2009) in the coastal Gulf of Maine (depth $<50 \mathrm{~m}$ ). To investigate spatial dynamics in response to Hurricane Irene near inlets, wave-current dynamics during the 1st maximum ebb, flood, and 2nd maximum ebb (GMT 16:00 08/27, 00:00 and 18:00 $08 / 28$ ) will be analyzed in the next subsection.

\subsection{Wave-current dynamics in the MCBs and their inlets during Hurricane} Irene

Fig. 5 depicts the spatial distributions of current and wave fields during Hurricane Irene. By dividing the MCBs into four spatially distinct regions (borders are indicated by the blue polygons in Fig. 1b-c), it was found that currents in the coastal ocean and within the inlets were significantly stronger than those inside the lagoon (Fig. 6a). Because large volumes of water funneled into the lagoon during maximum flood, the current velocity from the coastal ocean at $0.9 \mathrm{~m} / \mathrm{s}$ increased to $1.9 \mathrm{~m} / \mathrm{s}$ within the OCI. Given the inconformity between the incoming current and inlet orientation, the current speed reduced to half when passed through the CI. Due to the bottom friction and depth-induced breaking, waves propagating from the coastal ocean with a significant wave height of $4.6 \mathrm{~m}$ were reduced to less than half within the inlets. In the coastal ocean, circulation was synergistically controlled by the complex wind-wave-tide-bathymetry interactions, whereas ocean swells were mainly regulated by water depth. The spatial variation of wind-induced waves and circulation in the lagoon was discernible, presumably caused by the complex shallow-water processes (Ganju et al., 2017; Beudin et al., 2017). Given that an inlet represents the geographic and dynamic interface between the lagoon and coastal ocean, inlet wave-current dynamics were discussed further below.
During the 1st maximum ebb, currents along Isle of Wight Bay's eastern coast $(0.6-1.2 \mathrm{~m} / \mathrm{s})$ mainly flowed toward Sinepuxent Bay, leading to a relatively weaker current receding through the adjacent inlet. During maximum flood, massive amounts of water in the coastal ocean $(0.6-1.2 \mathrm{~m} / \mathrm{s})$ funneled into the OCI $(2.4-3.0 \mathrm{~m} / \mathrm{s})$ and divided into the upper and lower bays with a reduced intensity $(1.2-2.1 \mathrm{~m} / \mathrm{s})$. Owing to the concurrence of strong ebb currents and offshore winds during the 2nd maximum ebb, an appreciable jet with speeds up to $2.4-3.0 \mathrm{~m} / \mathrm{s}$ developed at the entrance of the OCI. Regulated by the unique inlet geometry, ocean swells were restricted within the inlets. Behind inlets and in the lagoon, wave dynamics were dominated by the overlying winds and refracted by the water depth variation in the shallow regions near the coast. During maximum flood, water surface elevations within the CI and OCI were significantly reduced from 1.2 and $0.8 \mathrm{~m}$ to $0.3 \mathrm{~m}$ in the lagoon. When the floodwater receded through the paired inlets at the $2 \mathrm{nd}$ maximum ebb, there was a $0.8 \mathrm{~m}$ drop in water surface elevation from the lagoon to coastal ocean. Fluctuations of water surface elevation and thus the local water depth are critical to the depth-induced wave breaking through the process of wave-current interactions. The effects of local winds, wave-current interactions, and inlet closure on inlet dynamics during Hurricane Irene were discussed in the next section.

\section{Discussion}

\subsection{Effect of local winds on inlet and its wave dynamics}

During the 1st maximum ebb, tidal currents were relatively weak $(0.6-1.2 \mathrm{~m} / \mathrm{s})$ and local winds were moderately strong $(\sim 13 \mathrm{~m} / \mathrm{s})$, see Fig. 7a1-2. Consequently, wind-induced currents (Case CW1 minus CW2, see Table 2) were pronounced in Sinepuxent Bay (up to $1.5 \mathrm{~m} / \mathrm{s}$ ) and within the tidal channels behind the CI $(0.6-0.9 \mathrm{~m} / \mathrm{s})$. Fig. 8 shows the calculated depth-integrated water transport fluxes (DWTFs) across the inlets with and without local winds. The periodical variation of DWTF in temporal space reflected the modulated effect from the M2 tide. During the 1 st maximum ebb, wind-induced DWTFs across the OCI and CI reached up to -424 and $3325 \mathrm{~m}^{3} / \mathrm{s}(-206 \%$ and $87 \%)$, see Table 4. Due to the positive relationship between the DWTF and current velocity (Eq. (5)), wind-induced current near the inlet was also fairly intense. At this tidal phase, wind-induced DWTFs across the OCI and CI were positive and negative respectively, depending on the level of agreement between the wind direction and inlet orientation (e.g., parallel, perpendicular, or oblique). This finding is consistent with that of Kang et al. (2017), who stated that substantial exchanges across the inlet were strongly associated with wind direction and specific inlet geometry. During the 2nd maximum ebb, the weakened winds posed a reduced effect on inlet circulation by $20 \%$ and $-8 \%$ DWTF (i.e., with and without local winds) across the OCI and CI. In general, wind-induced DWTF across the wide CI was greater than that across the narrow OCI.

A recent study from Ganju et al. (2017) demonstrated that wave dynamics in Chincoteague Bay were largely determined by the overlying winds (e.g., speed, fetch, and direction). Likewise, our results indicate that wind-waves in the lagoon and behind inlets, which are beyond the reach of ocean swells, are dominated by local winds (Fig. 7c1-2 and d1-2). Because of longer fetch conditions, significant wave height behind the $\mathrm{CI}(0.4-0.8 \mathrm{~m})$ was higher than that behind the OCI (below $0.4 \mathrm{~m}$ ). Ganju et al. (2017) reported that wind-waves could reach $0.5 \mathrm{~m}$ under storm conditions in Chincoteague Bay. In our study, the significant wave height increased from $0.4 \mathrm{~m}$ in the lagoon to $1.9 \mathrm{~m}$ within the OCI during the maximum flood of Hurricane Irene (Fig. 6b). Within the inlets, ocean swells played a major role and local winds were of secondary importance (e.g., reflected by the disagreement between the wind direction and mean wave direction). In the coastal ocean, 


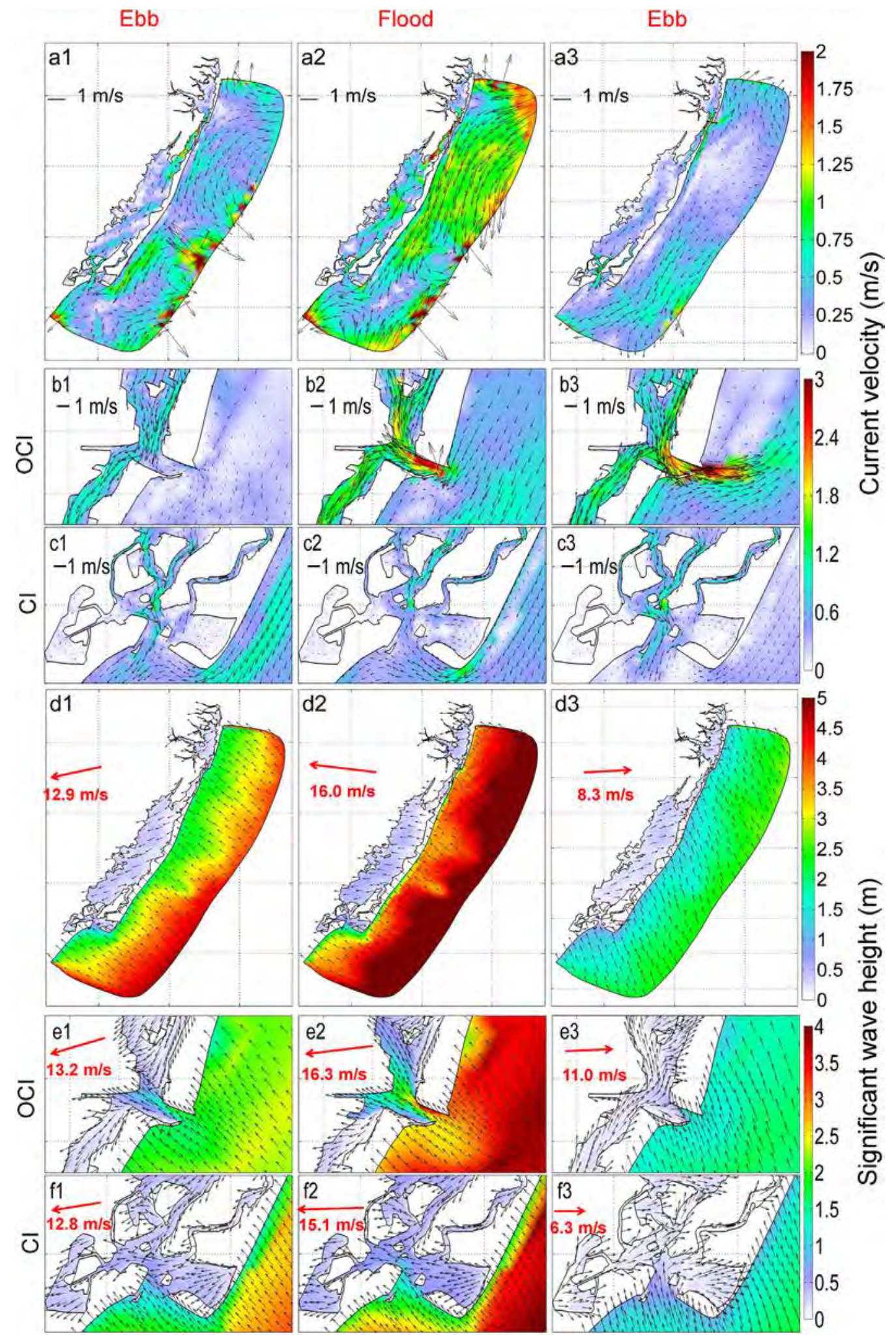

Fig. 5. Spatial distributions of (a1-3, b1-3, and c1-3) the depth-averaged current velocity and (d1-3, e1-3, and f1-3) significant wave height from the baseline 3D wave-current coupled model during Hurricane Irene. Red arrows in (d1-3, e1-3, and f1-3) indicate the spatially averaged wind speeds. (For interpretation of the references to color in this figure legend, the reader is referred to the web version of this article.)

wind-induced waves were quite weak and ocean swells were prevalent. A thorough discussion supporting the aforementioned finding was given in the following subsections. The observed significant wave height, peak wave period, and mean wave direction at WIS were 0.85 /
$0.79 \mathrm{~m}, 9.8 / 8.3 \mathrm{~s}$, and $158 / 1680$ in $2011 / 2014$, which represented the typical features of ocean swells. Therefore, wave dynamics in the inlet and coastal ocean (swell dominance) are highly complex and clearly different from those in the lagoon (wind-sea conditions). 

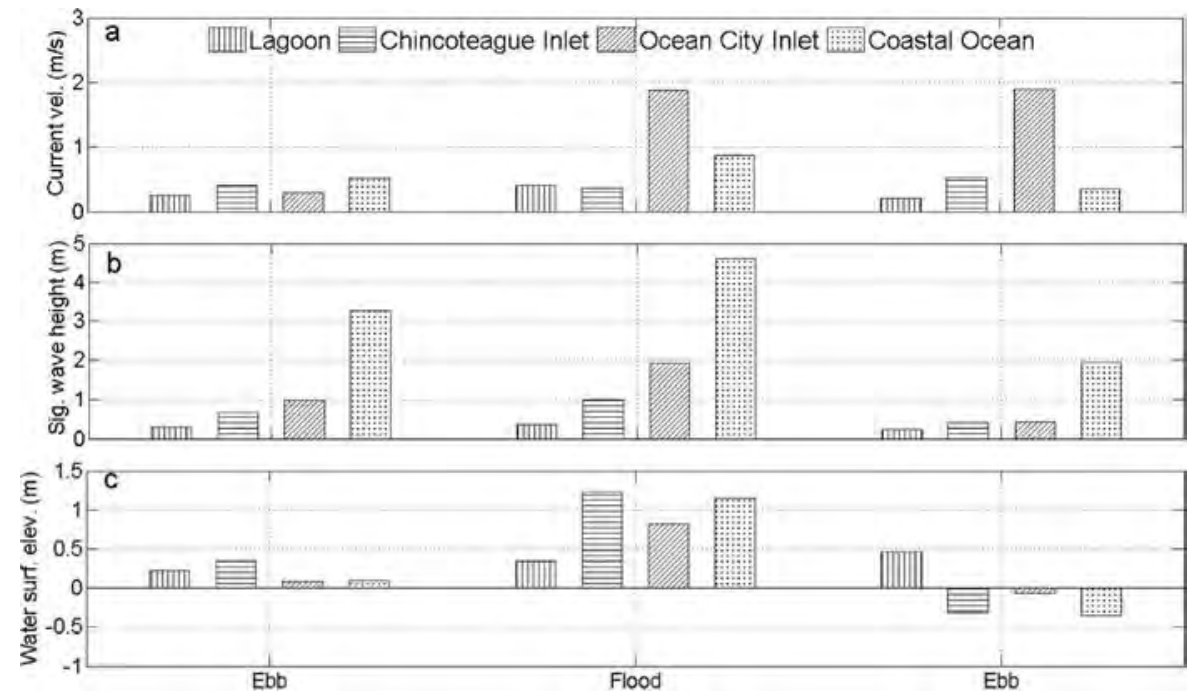

Fig. 6. (a) The depth-averaged current velocity, (b) significant wave height, and (c) water surface elevation in the lagoon, Chincoteague Inlet, Ocean City Inlet, and coastal ocean from the baseline 3D wave-current coupled model during Hurricane Irene.

\subsection{Effect of wave-current interactions on inlet dynamics}

Fig. 3d1 shows the time series of water surface elevations produced from the circulation-only and wave-current coupled models (Cases C1 and CW1) versus observed values. In general, both models replicated the temporal variations of the observed water surface elevation well. Under normal conditions within the simulation period, Cases C1 and CW1 showed similar skill in reproducing the water surface elevation (0.92-0.93 for CC, $10-12 \mathrm{~cm}$ for RMSD, 0.92-0.94 for WS). During Hurricane Irene, underestimation of the maximum water surface elevation from Case C1 $(20 \mathrm{~cm}$ or $20 \%)$ was reduced by half with the inclusion of wave-current interactions (Case CW1). This improvement was attributed to the wave-induced setup (Dodet et al., 2013). Fig. 9a1-2, b1-2, a3-4, and b3-4 show the wave-induced currents and radiation stress gradients, the spatial agreement of which suggests that radiation stress is significant to the wave-induced currents. This conclusion was consistent with previous findings in shallow lagoon-inlet-coastal ocean systems elsewhere such as the Albufeira Lagoon (Dodet et al., 2013) and New River Inlet (Chen et al., 2015). It was clear that wave-induced longshore currents near the OCI (up to $1.5 \mathrm{~m} / \mathrm{s}$ ) were greater than those near the $\mathrm{CI}$ (below $0.9 \mathrm{~m} / \mathrm{s}$ ). Moreover, the $R B$ for the DWTF (i.e., product of the cross-inlet velocity and transect) across the OCI generated by waves (Case CW1 minus C1 in Table 4) was correspondingly higher than that across the CI (grand means at $23 \%$ versus $6 \%$ ). To separately assess the model skill in simulating the tidal and non-tidal components of the water surface elevation, the classical harmonic analysis tool using the T_TIDE package (Pawlowicz et al., 2002) was conducted (Fig. 3d2-3). Tidal surface elevation fluctuated periodically, whereas the non-tidal component was pronounced under hurricane conditions. The statistical scores indicated that both models performed better in simulating the tidal signal than the non-tidal signal (0.94-0.96 versus 0.83 for $C C$; $10-11$ versus $14-15 \mathrm{~cm}$ for $R M S D$ ).
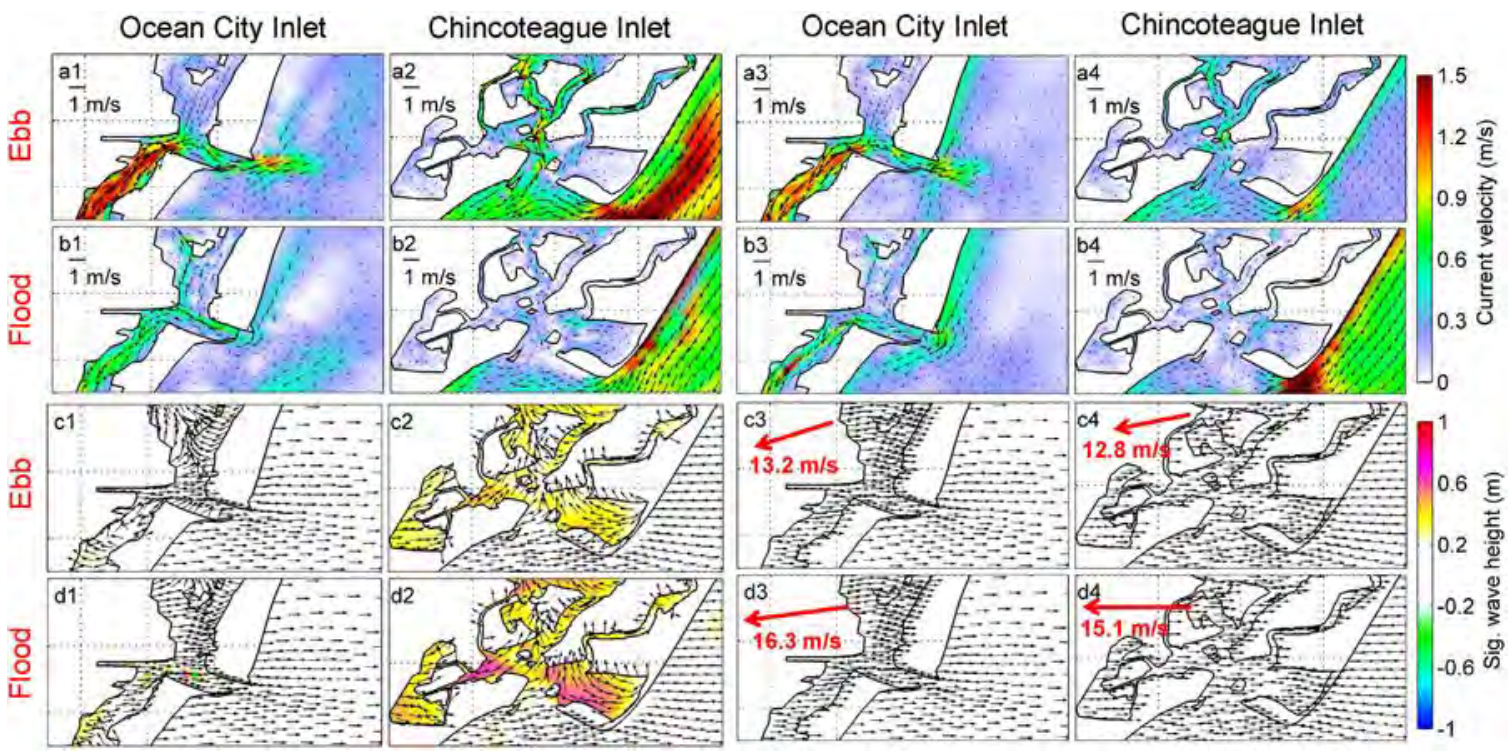

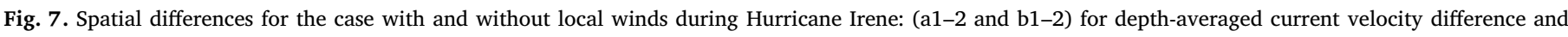

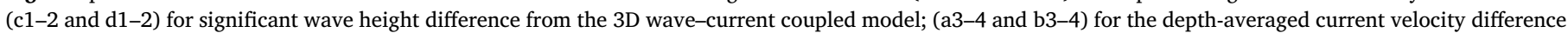

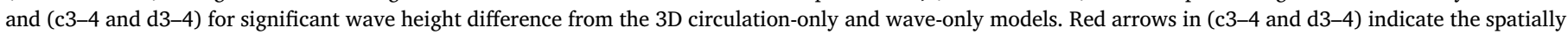
averaged wind speeds. (For interpretation of the references to color in this figure legend, the reader is referred to the web version of this article.) 

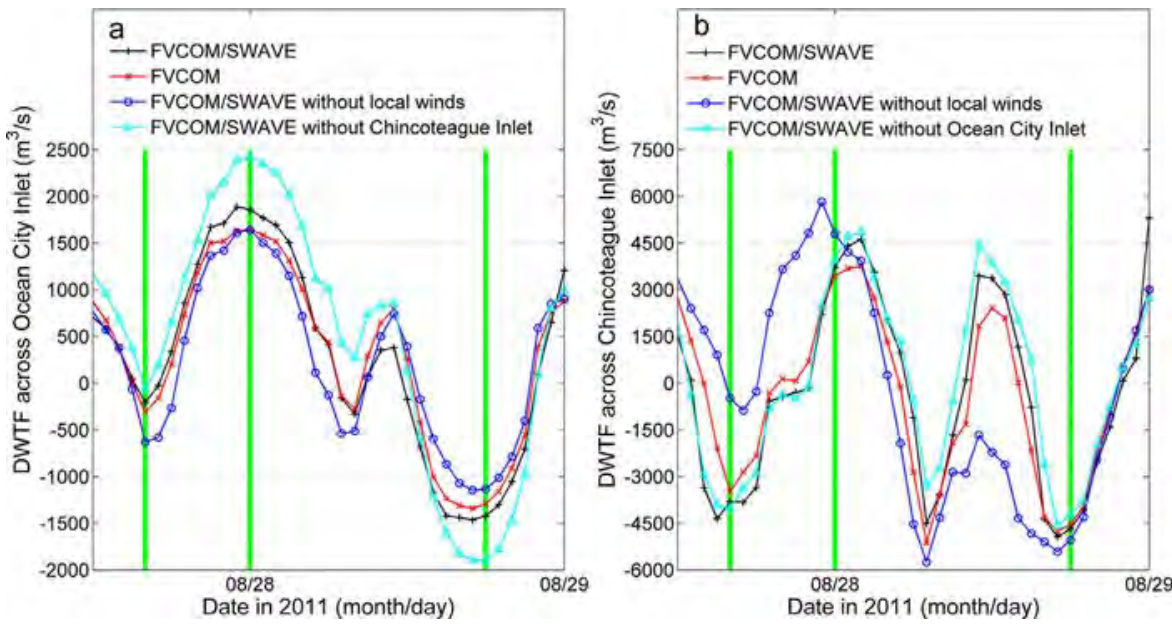

Fig. 8. Time series of DWTFs calculated from the baseline wave-current coupled model (FVCOM/ SWAVE), and that without wave-current interactions (FVCOM), local winds, and the remote inlet across the (a) OCI and (b) CI during Hurricane Irene. Green bars indicate the moments at the 1st maximum ebb, flood, and 2nd maximum ebb. (For interpretation of the references to color in this figure legend, the reader is referred to the web version of this article.)

Table 4

Calculated DWTFs across inlets, $R B$ scores and differences between the simulations and baseline run (Case CW1) during Hurricane Irene.

\begin{tabular}{|c|c|c|c|c|c|c|c|}
\hline \multirow[t]{2}{*}{ Phase } & \multirow[t]{2}{*}{ Case } & \multicolumn{2}{|c|}{ DWTF $\left(\mathrm{m}^{3} / \mathrm{s}\right)$} & \multicolumn{2}{|l|}{$R B$} & \multicolumn{2}{|c|}{ Difference $\left(\mathrm{m}^{3} / \mathrm{s}\right)$} \\
\hline & & OCI & CI & OCI & $\mathrm{CI}$ & OCI & $\mathrm{CI}$ \\
\hline \multirow[t]{5}{*}{ 1st maximum Ebb } & $\mathrm{C} 1$ & -308 & -3485 & $-50 \%$ & $8 \%$ & -103 & 321 \\
\hline & CW1 & -206 & -3806 & / & / & / & / \\
\hline & CW2 & -630 & -481 & $-206 \%$ & $87 \%$ & -424 & 3325 \\
\hline & CW3 & / & -4018 & / & $-6 \%$ & / & -212 \\
\hline & CW4 & -65 & / & $68 \%$ & / & 41 & / \\
\hline \multirow[t]{5}{*}{ 1st maximum Flood } & $\mathrm{C} 1$ & 1648 & 3439 & $-11 \%$ & $-8 \%$ & -209 & -287 \\
\hline & CW1 & 1857 & 3726 & / & / & / & / \\
\hline & CW2 & 1641 & 4801 & $-12 \%$ & $29 \%$ & -216 & 1075 \\
\hline & CW3 & / & 3965 & / & $6 \%$ & / & 238 \\
\hline & CW4 & 2419 & / & $30 \%$ & / & 562 & / \\
\hline \multirow[t]{5}{*}{ 2nd maximum Ebb } & $\mathrm{C} 1$ & -1291 & -4532 & $9 \%$ & $3 \%$ & 129 & 140 \\
\hline & CW1 & -1420 & -4677 & / & / & / & / \\
\hline & CW2 & -1134 & -5042 & $20 \%$ & $-8 \%$ & 286 & -370 \\
\hline & CW3 & / & -4220 & / & $10 \%$ & I & 452 \\
\hline & CW4 & -1895 & I & $-33 \%$ & / & -474 & / \\
\hline
\end{tabular}
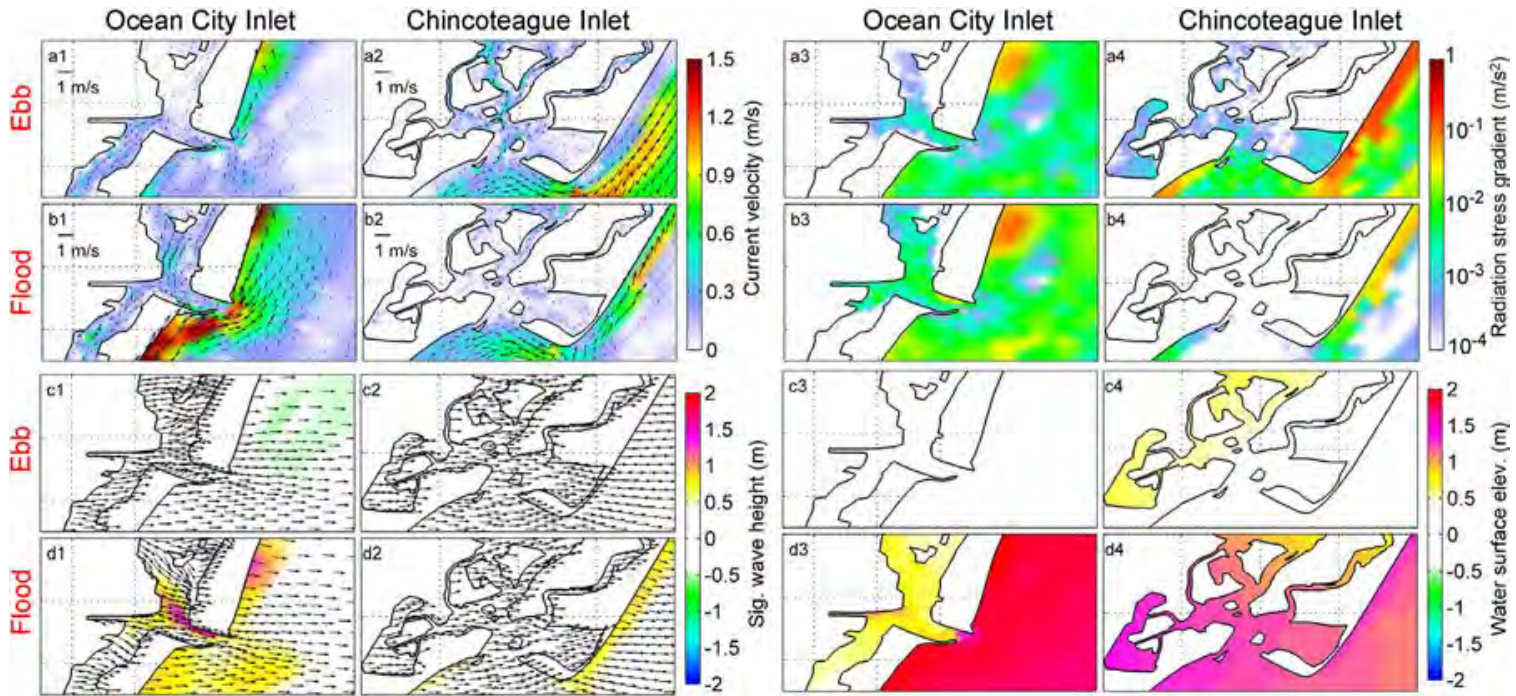

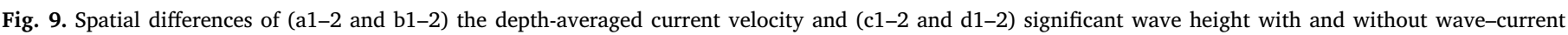

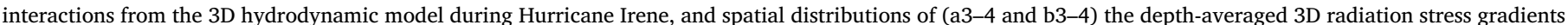
and (c3-4 and d3-4) water surface elevation from the baseline 3D wave-current coupled model. 


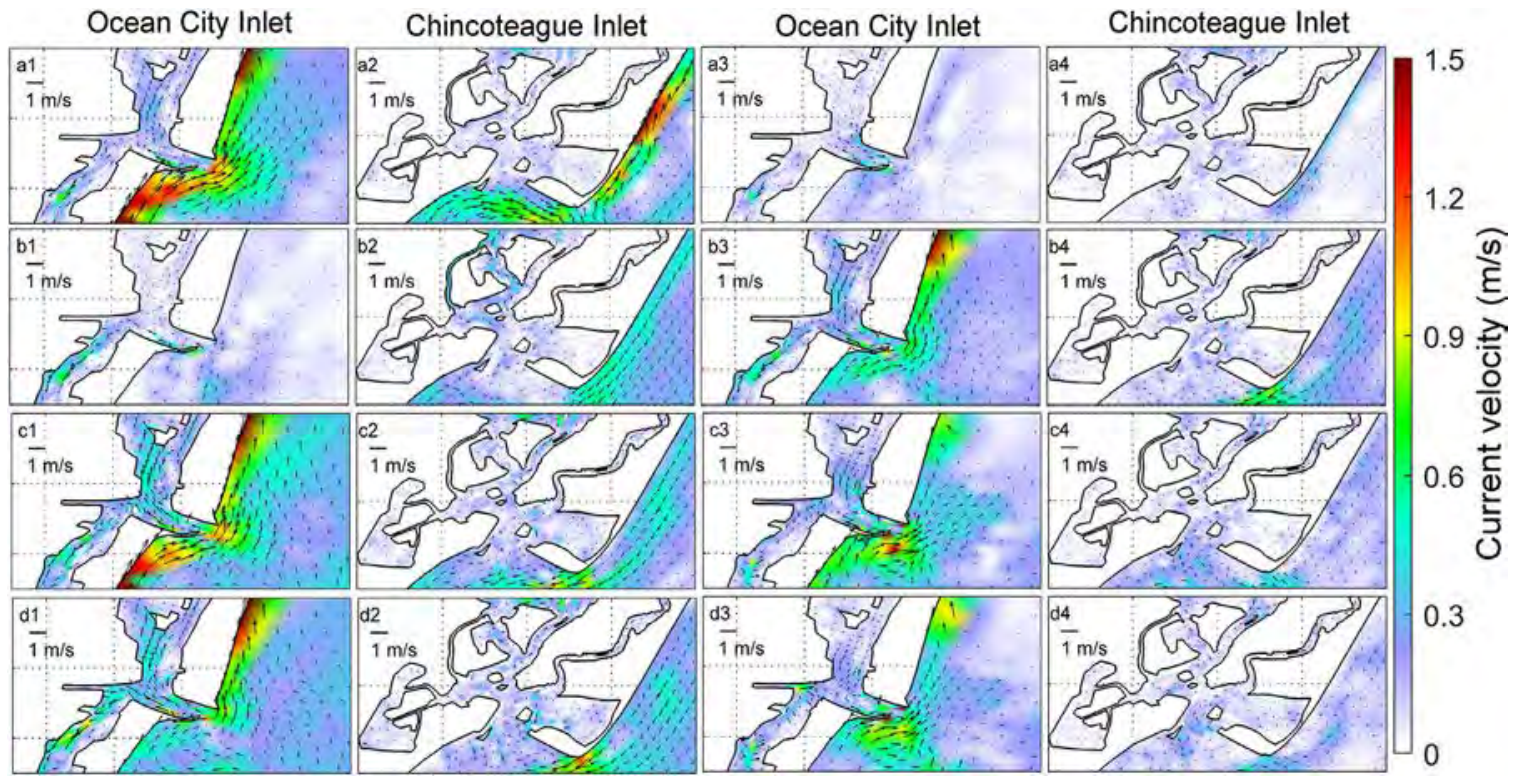

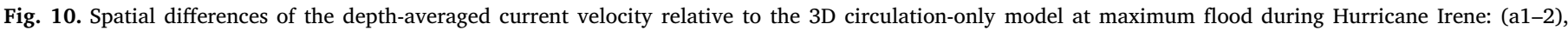

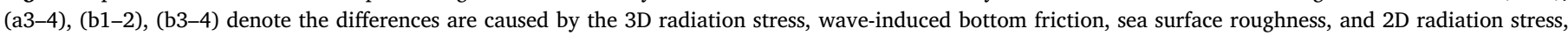

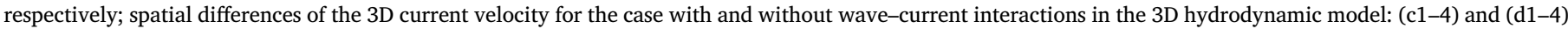

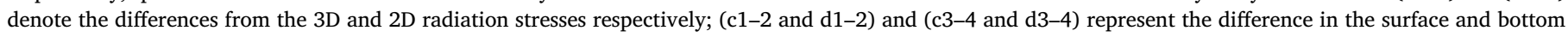
layers respectively.

Further analysis using the cross-correlation function indicated that the model-to-data phase mismatch of the water surface elevation was caused by the inaccurate estimation of the non-tidal component.

Wave parameters outside the OCI (Fig. 3e-g) were well reproduced by both the wave-only and the wave-current coupled models (Cases W1 and CW1). By replacing Case W1, Case CW1 reduced the discrepancies of the peak significant wave height at 3.58 and $2.34 \mathrm{~m}$ during Hurricane Irene and Tropical Storm Lee from -0.15 and $0.85 \mathrm{~m}(-4.2 \%$ and $36.3 \%)$ to -0.08 and $0.3 \mathrm{~m}(-2.2 \%$ and $12.8 \%)$, respectively. Modeled peak wave period and mean wave direction were similar between Cases W1 and CW1 (i.e., depth/current induced wave frequency shift and refraction were weak) at the coastal station with $11.1 \mathrm{~m}$ water depth. During maximum flood, incorporating the positive water surface elevation into the coupled system led to greater values of significant wave height $(0.5-1.5 \mathrm{~m})$ near the OCI (Fig. 9d1). This can be explained by the fact that the enhanced local water depth allows for a higher upper bound for the maximum possible wave height at a fixed breaker index.

\subsection{Individual wave effects and $2 D / 3 D$ radiation stress on inlet circulation}

To explore individual wave effects on circulation, Cases C2 and W2 were added by excluding local winds from the circulation- and waveonly models. Difference of wind-induced currents with and without wave-current interactions (Cases CW1 minus CW2 and C1 minus C2) was discernible near the inlet and in the coastal ocean (Fig. 7), which matched the regions with strong intensity of wave-induced currents (Fig. 9a1-2 and b1-2). This finding suggests that wave-current interactions play an important role in the wind-induced current, which motivated us to examine further the individual effects of wave-induced radiation stress, bottom friction, and sea surface roughness (Cases CW5-CW7) on the circulation at the maximum flood, when local winds, waves, currents, and wave-current interactions were strong. Along southern Assateague Island, currents generated by the wave-induced radiation stress, bottom friction, and sea surface roughness (Fig. 10a1-2, a3-4, and b1-2) were 0.6-1.5, 0-0.3, and 0.3-0.6 m/s. The close agreement of the spatial current distribution between Cases CW1 and CW5 (Figs. 9b1-2 and 10a1-2) indicated that radiation stress played a more important role in the nearshore dynamics than wave- induced bottom friction and sea surface roughness (Olabarrieta et al., 2011; Niu and Xia, 2017). Theoretical studies (Mellor, 2013, 2015) suggested that the three-dimensional (3D), depth-dependent radiation stress decreased nonlinearly from surface to bottom for the case of deep water (e.g., as $K D \rightarrow \infty, S_{\alpha \beta} \sim \frac{E k_{\alpha} k_{\beta}}{k} e^{2 k D \varsigma}$, where $K D$ is dimensionless water depth and $\varsigma$ decreases from 0 to -1 ). In addition to a nonlinearly and vertically decreasing roller term in the shallow water $\left(\frac{k_{\alpha} k_{\beta}}{k^{2}} \frac{C^{2}}{L} A_{R}\left[1-\tanh \left(\frac{2 \zeta}{\gamma}\right)^{4}\right]\right)$, the radiation stress $S_{x x}$ or $S_{y y}$ increases with water depth while $S_{x y}$ or $S_{y x}$ remains as a constant throughout the water column (e.g., as $K D \rightarrow 0, S_{x x}$ or $S_{y y} \sim \frac{E}{D}(1-\varsigma)$ and $S_{x y}$ or $S_{y x} \sim \frac{E k_{x} k_{y}}{k^{2}} \frac{1}{D}$ ). Under storm conditions, wave-induced current in the large-scale Lake Erie was reported below $0.2 \mathrm{~m} / \mathrm{s}$ (Niu and Xia, 2017), whereas its magnitude reached $1.5 \mathrm{~m} / \mathrm{s}$ near the $\mathrm{OCI}$ in the smaller MCBs. Although the bottom wave orbital velocity was up to $0.9-1.2 \mathrm{~m} / \mathrm{s}$ (not shown herein), current variation caused by the wave-induced bottom friction was limited to some extent and not pronounced. Based on the parameterized formula proposed by Soulsby (1997), lower limit of the combined bottom stress $\tau_{c w}$ was equal to the current-induced stress $\tau_{c}$ (i.e., no wave stress $\tau_{w}$ ), and the upper bound of $\tau_{c w}$ was confined to the double values of $\tau_{c}$, see details in Eq. (2e). Based on Eq. (2b), the wave friction factor $f_{w}$ is the key parameter that determines the wave-induced bottom frictional stress. Given that $f_{w}$ is highly dependent upon the physical roughness length $k_{N}$, it would likely be a worthwhile future endeavor to estimate a more accurate $k_{N}$ with the consideration of the damping effect exerted by seagrass meadows (Beudin et al., 2017).

To compare the $3 \mathrm{D}$ and $2 \mathrm{D}$ radiation stresses in the $3 \mathrm{D}$ hydrodynamic model (Cases CW1 and CW8), the depth-averaged wave-induced currents from Case CW8 are shown in Figs. 10b3-4. Overall, both cases produced a similar spatial distribution of the depth-averaged wave-induced currents. It has been well recognized that the $3 \mathrm{D}$ radiation stress formulation is equivalent to the $2 \mathrm{D}$ version when vertically integrated (Mellor, 2015). However, application of a 3D radiation stress was necessary when investigating the vertically inhomogeneous 3D circulation under strong storm conditions (Bolaños et al., 2011; Sheng and Liu, 2011; Moghimi et al., 2013). In the current study, the waveinduced circulation in the surface and bottom layers was compared between the $3 \mathrm{D}$ and $2 \mathrm{D}$ radiation stress formulations (Figs. 10c1-4 and 


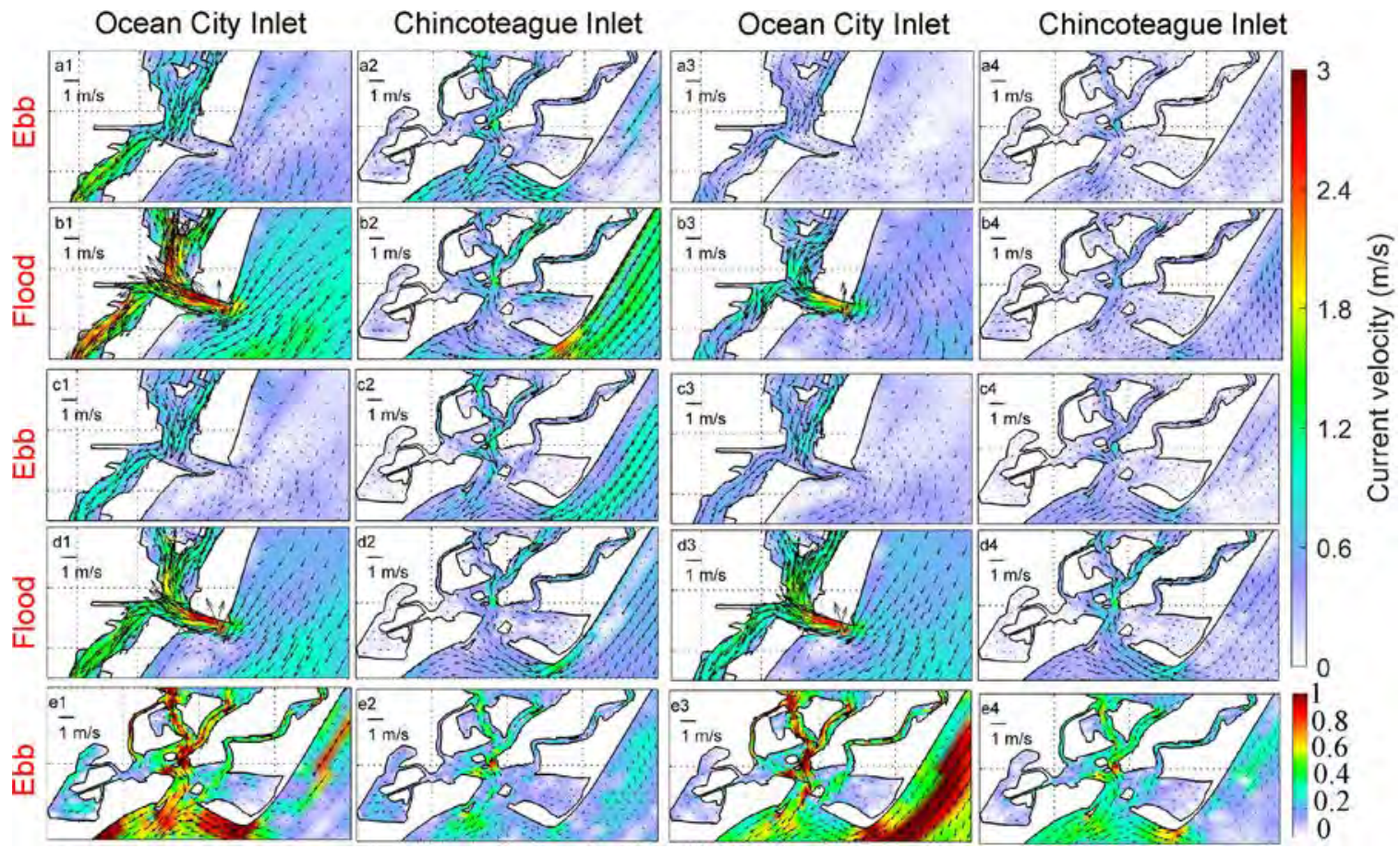

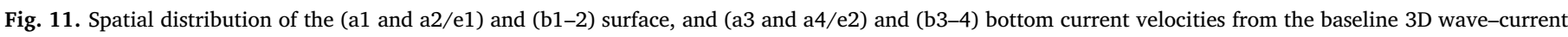

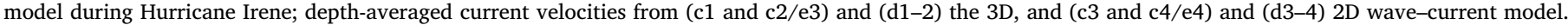

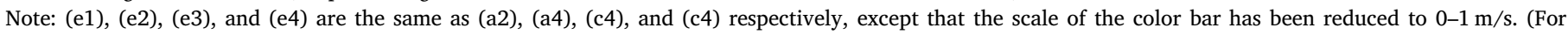
interpretation of the references to color in this figure legend, the reader is referred to the web version of this article.)

d1-4). In the surface layer, wave-induced longshore current in both cases was significantly stronger than that in the offshore region (up to $1.5 \mathrm{~m} / \mathrm{s}$ versus less than $0.3 \mathrm{~m} / \mathrm{s}$ ), especially using the 3D radiation stress. In the bottom layer, wave-induced current was relatively weak compromised by the bottom friction. Although the wave-induced surface/bottom current between the 2D and 3D radiation stress formulations followed a consistent direction, they showed appreciable variations in the magnitude. Given that the newly developed 3D radiation stress representation (Mellor, 2015) is more realistic and physically meaningful than the 2D formulation for practical applications (e.g., vertical variability of the wave-induced currents), it was incorporated into the 3D wave-current coupled system.

To further examine the vertically inhomogeneous inlet circulation, Fig. 11 presents spatial distributions of the surface, bottom, and depthaveraged currents produced from the 3D and 2D wave-current coupled models (Cases CW1 and CW9). The depth-averaged circulation was comparable in the shallow regions of the lagoon and inlets $(0-0.2 \mathrm{~m} / \mathrm{s})$ between the 2D and 3D models; some differences were detected at the deep coastal region, where radiation stress gradient and its induced depth-averaged current were relatively weak (Figs. 9b4 and 10a2). When the surface current was exceedingly stronger than the bottom flow in the deep channels behind the CI (Fig. 11a2/e1 and a4/e2), subtle variations were found correspondingly over the same region at $0.2-0.4 \mathrm{~m} / \mathrm{s}$ (Fig. 11 c2/e3 and c4/e4). The finding that a vertically uniform current distribution assumed from the 2D model is not satisfied for the 3D model in the deep channels was supported by Purkiani et al. (2015) at the tidal inlet of the Wadden Sea. Because the resolving ability of the vertically inhomogeneous circulation is critical to an accurate estimation of the water and salt fluxes across the inlet (Kang et al., 2017; Beudin et al., 2017), the 3D model (Case CW1) was adopted for further discussion. Overall, it is clear that the Mellor (2015) $3 \mathrm{D}$ radiation stress formulation is suitable to the wave-current studies in the MCBs. Although a more integrated coupling system that includes a wave boundary layer (Fan et al., 2009) or air-sea momentum flux budget model (Du et al., 2017) is a favorable application for additional investigation of the highly complex wind-wave-current-bathymetry interactions, it is beyond the scope of this manuscript to include such a model.

\subsection{Effect of inlet closure on inlet dynamics}

Given that an inlet serves as the geographic and dynamic interface connecting the lagoon and coastal ocean, numerical experiments by hypothetically closing one of the paired inlets and examining the dynamics remotely are significant for practical applications and scientific curiosity. By artificially closing the inlet, the water flux entering the lagoon and flooding nearby regions under extreme conditions can be prevented. The idea of building mobile gates at the entrance during high tides was initially proposed by Munk and Munk (1972) for the Venetian Lagoon, Italy. The corresponding project officially started in 1991 and is expected to be operational in 2020 (http://www.watertechnology.net/projects/mose-project/). Nevertheless, inlet closure may lead to ecosystem disruptions and declined biodiversity, such as that reported in the Tijuana River Estuary (Zedler et al., 2001). It would be a worthwhile endeavor for future research to perform a comprehensive analysis (e.g., scientific practicability, ecosystem biodiversity, and socioeconomic effects) on the advantages and disadvantages of constructing such flood-limiting gates at the inlets of the MCBs.

Fig. 12a1-4, b1-4, c1-4, and d1-4 show the variations of current velocity and significant wave height by hypothetically closing the OCI or CI (the baseline Cases CW1 minus CW3 or CW1 minus CW4). When either inlet was closed, circulation and wave dynamics behind the corresponding inlet were strongly altered. At the 1 st maximum ebb, the hypothetical closure of the CI led to $0.6-0.9 \mathrm{~m} / \mathrm{s}$ variations of the current velocity remotely and a $68 \%$ enhancement of the DWTF across the OCI (Table 4). In contrast, variations of the current velocity (less than $0.3 \mathrm{~m} / \mathrm{s}$ ) and DWTF (6\%) within the CI were relatively weak when the OCI was closed. The asymmetric responses of inlet circulation to the closure of the remote inlet were strongly associated with the inlet width and the alignment level between the inlet orientation and bay axis. 


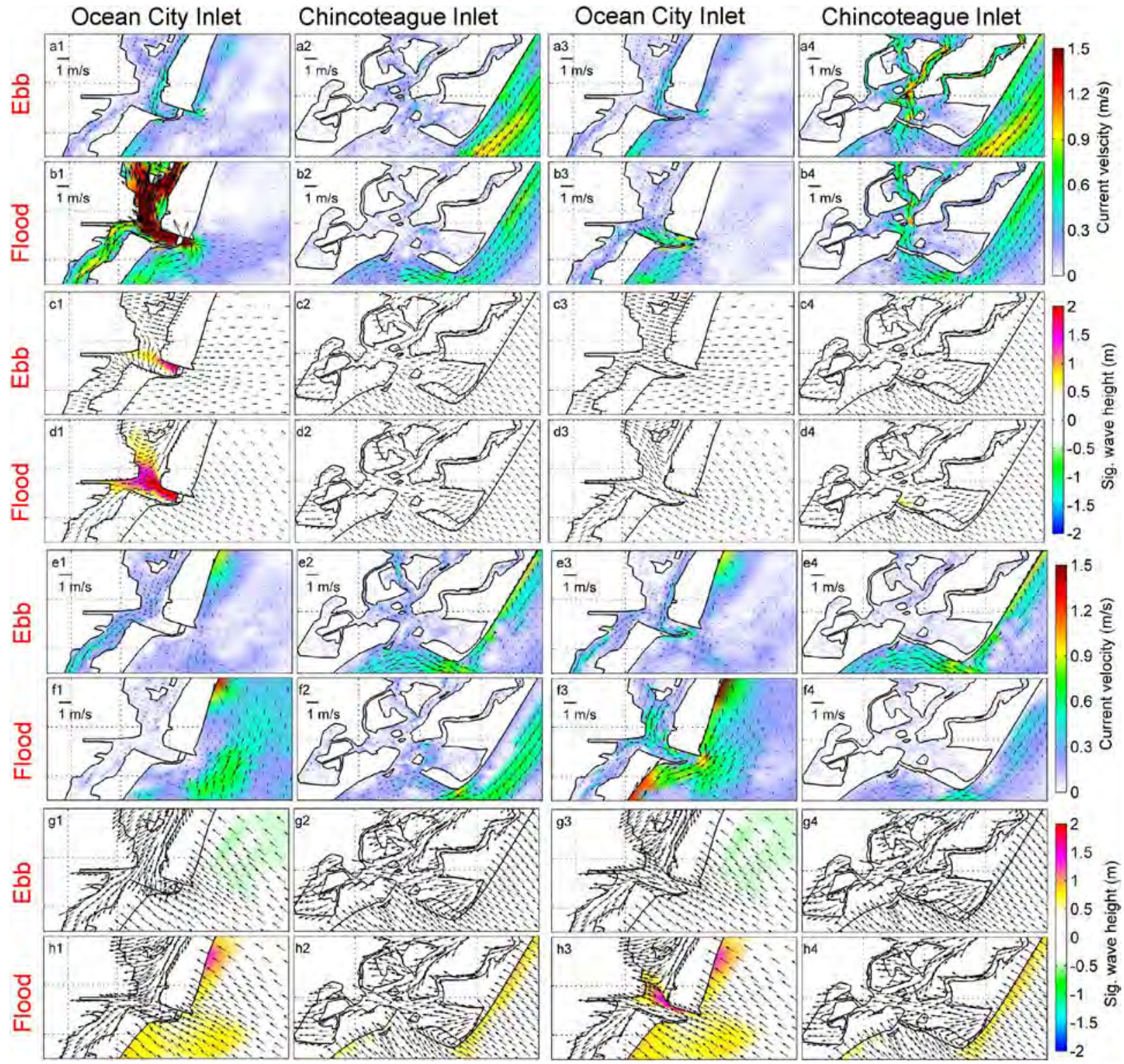

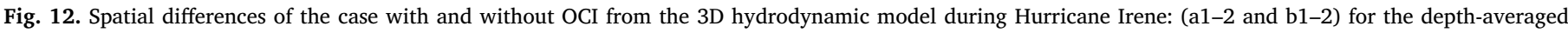

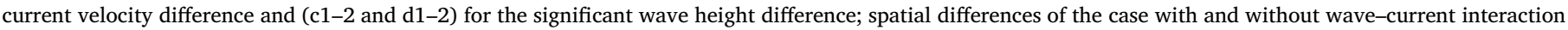

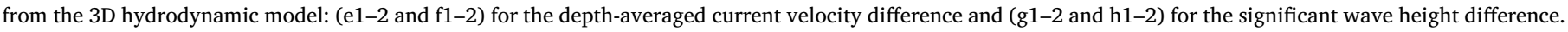
Columns 3 and 4 are the same as 1 and 2, except that the CI is closed.

Changes of significant wave height were negligible by shutting down the remote inlet, resembling the physics of a single-inlet system. Given the site-specific characteristics of the inlet, circulation near the small and narrow OCI follows the pattern of a double-inlet system, whereas it behaves like a single-inlet system for the larger and wider CI. To explore wave-current interactions under the hypothetical single-inlet system, the uncoupled model was run by artificially shutting down the OCI or CI (Cases C3/W3 or C4/W4). Fig. 12e1-4, f1-4, g1-4, and h1-4 show the residual currents and waves generated by wave-current interactions in the context of single-inlet systems. Because the closure of an inlet physically blocks the communication between the lagoon and coastal ocean, wave-induced currents behind the given inlet become rather weak (cf. Fig. 9a1-2 and b1-2). In general, inlet wave dynamics remained similar between the double-inlet and hypothetical single-inlet systems (i.e., comparing Cases CW1 minus W1, CW3 minus W3, and CW4 minus W4). Occasionally, the effect of wave-current interactions on wave dynamics became quite weak behind the closed OCI (Case CW3 minus W3) at maximum flood. Because the closure of the OCI prevented the tidal currents from funneling into the adjacent inlet (i.e., positive water surface elevation), depth-induced wave breaking in the wave-current coupled model with a nearly fixed water depth behind the closed inlet remained unchanged.

Due to the dynamic connectivity between inlets, dynamics of the shallow lagoon-inlet-coastal ocean system with multiple inlets (e.g., the Rio Formosa coastal lagoon in the southern coast of Portugal and the western Dutch Wadden Sea) are complex. Fabião et al. (2016) and Duran-Matute et al. (2016) indicated that remote transport of the water flux was synergistically controlled by tide, wind, shallow-water process, and inlet geometry. By closing the remote inlet, variations of the circulation near the OCI and CI were at different levels (i.e., comparing Cases CW1 minus CW3 and CW1 minus CW4 in Fig. 12 a2-3 and b2-3) due to distinct inlet characteristics. Overall, inlet wave-current interactions are weakly modified by closing the remote inlet. The moderate effect of inlet closure on the remote circulation was due to the strong interconnection between the inlets in the small-scale lagoon (Fabião et al., 2016); this effect was weak for wave dynamics because of 


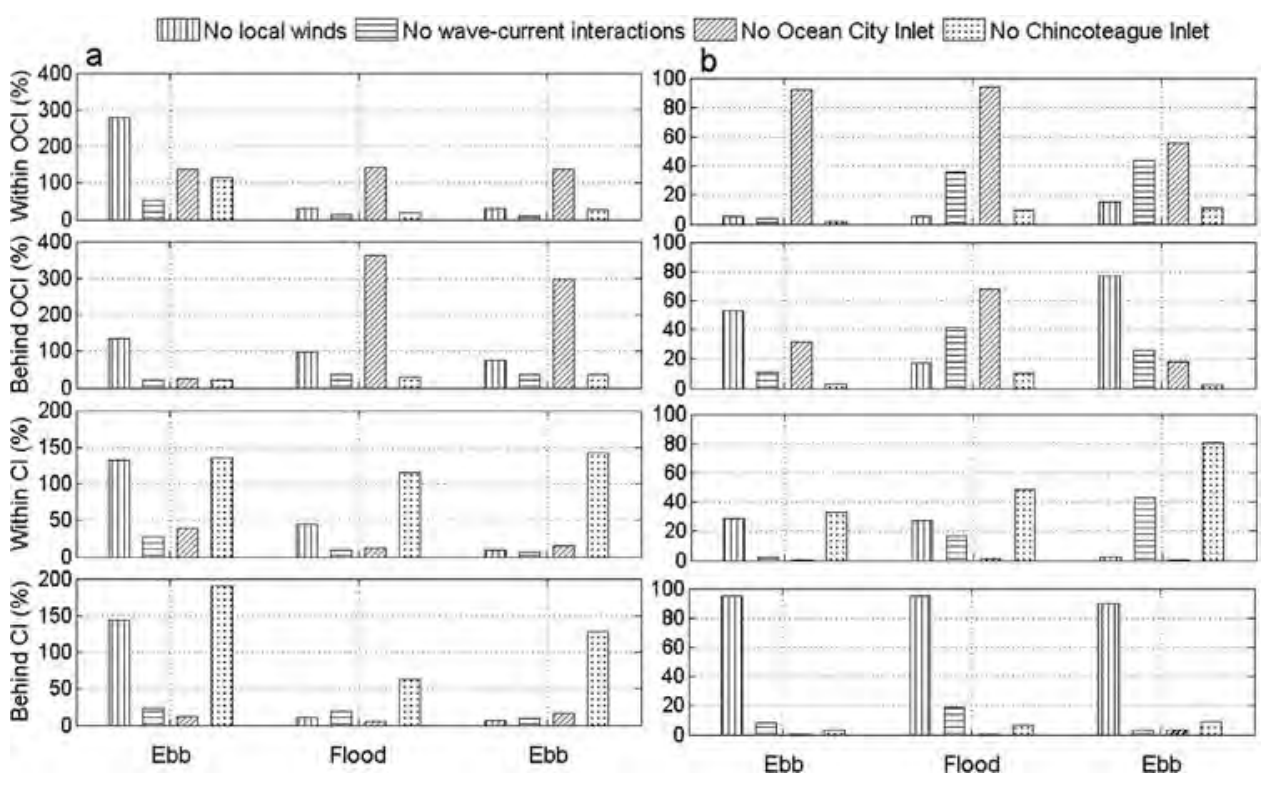

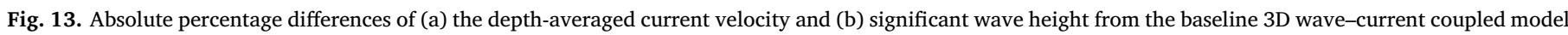
during Hurricane Irene but without local winds, wave-current interactions, OCI, and CI, respectively.

intensive shallow-water dissipation and breaking process (Olabarrieta et al., 2011). With stronger connectivity (e.g., greater inlet width, shorter distance between inlets, or better alignment of inlet and current), the dynamic linkage and interactions of the geographically separated inlets in the lagoon-inlet-coastal ocean system are expected to be important.

\subsection{Leading terms of inlet dynamics}

To quantify variations of the current velocity and significant wave height due to the exclusion of local winds, wave-current interactions, and inlet closure, their absolute percentage differences (APDs) relative to the baseline run (Case CW1) are calculated (Fig. 13). Overall, APDs for the current velocities within and behind the OCI and CI were found to be greatest in Cases CW3 and CW4 (i.e., closing the OCI or CI), respectively. This finding indicates that tidal current is the key factor of inlet circulation. Occasionally, local wind-induced current was moderately strong at the 1st maximum ebb when tides were relatively weak. Wave dynamics were dominated by ocean swells within the paired inlets (e.g., the highest $A P D$ for the significant wave heights within the $\mathrm{OCI} / \mathrm{CI}$ from Case CW3/CW4). Given that APDs for current velocity were comparable by the removal of local winds, wave-current interactions, or the closure of remote inlet, these factors were of secondary importance to inlet circulation. Due to distinct inlet characteristics, the effects of closing the remote inlet on the circulation within the OCI or CI were different ( $54 \%$ versus $22 \%$ for $A P D$ ). Because of frequent water depth variations and strong wave-current conditions, effect of wave-current interactions on significant wave height was stronger within the OCI than that within the CI ( $28 \%$ versus $21 \%$ for $A P D$ ). Behind inlets, wave dynamics were mainly controlled by local winds with the highest $A P D$. On occasion, extremely strong ocean swells propagated into the OCI during maximum flood. Given that greater geographic dimensions promote the development of long-fetch winds, wind-waves behind the CI were more significant than those behind the OCI (93\% versus $49 \%$ for $A P D$ ). Considering various levels of alignment between the inlet orientation and the direction of the incoming ocean swell, influence of inlet closure on the nearby wave dynamics was unequal within the OCI and CI ( $80 \%$ versus $54 \%$ for $A P D)$. It can be concluded that closing any of the paired inlets has limited effects on the wave dynamics at the remote inlet; ocean swells and local winds are the leading terms of the wave dynamics within and behind inlets, respectively.

\section{Conclusions}

In this study, a high-resolution, wave-current coupled, three-dimensional (3D) model was successfully applied to the Maryland Coastal Bays and their paired inlets under hurricane conditions. Calibration and validation experiments against observations demonstrate that this system reasonably reproduces water surface elevation, current velocity, and wave parameters. During Hurricane Irene (2011), the wave-current dynamics and interactions near Ocean City Inlet (OCI) and Chincoteague Inlet (CI) have been discussed in detail and conclusions are summarized as follows:

(1) During maximum ebb/flood, massive amounts of water moved from/to the lagoon to/from coastal ocean through the paired inlets. The current across OCI is stronger than that across CI, while the depth-integrated water transport flux across $\mathrm{CI}$ is greater than that across OCI. Results suggest that tidal currents and ocean swells are primarily responsible for the circulation and wave dynamics within each inlet, respectively. Wave dynamics behind inlets are dominated by local winds and modulated by the shallow bathymetry. Local wind is also critical to the dynamics of inlet circulation, which are supplemented by the local wave-current interactions, particularly during maximum flood.

(2) With the inclusion of wave-current interactions, underestimations of the high water surface elevation mark $(1.01 \mathrm{~m})$ and the extreme value of significant wave height $(3.58 \mathrm{~m})$ during Hurricane Irene are reduced from $20 \mathrm{~cm}$ to $10 \mathrm{~cm}$ (by $10 \%$ ) and from $15 \mathrm{~cm}$ to $8 \mathrm{~cm}$ (by $2 \%$ ). Major processes of wave-current interactions include the radiation stress-induced setup and current, and water depth variation-induced wave breaking. Compared to the dominance of the radiation stress on nearshore dynamics (e.g., inlet circulation and longshore current in the shallow regions along the coast), waveinduced bottom friction and sea surface roughness are of secondary importance.

(3) By hypothetically closing one of the paired inlets, wave-current dynamics and interactions within the adjacent inlet are strongly altered, whereas they are weakly influenced from the remote site, particularly for the wave dynamics. This performance resembles that of a single-inlet system. Occasionally, circulation within OCI is moderately influenced by closing the CI, and this behavior follows the pattern of a double-inlet system. 
This 3D wave-current coupled model can be applied to similar lagoon-inlet-coastal ocean systems with multiple inlets elsewhere, such as the Great South Bay, New York, Barnegat Bay, New Jersey, and Indian River Lagoon, Florida. It would be worthwhile to design a more integrated system to explore the complex wave-current dynamics, especially when the inlet circulation is vertically inhomogeneous. In the future, a more detailed surface boundary condition model will consider the relative wind effect (i.e., the change of wind speed due to the ambient current), divide the air-sea momentum flux into subsurface current and surface waves, and use the turbulent stress for wave growth by subtracting the wave-induced stress from the total stress. Wave-current interaction is a complex issue, and the purpose of this manuscript is to investigate the significance of wave-current interaction and reveal its dynamics near the inlet during hurricane conditions. It would be a worthwhile endeavor to refine the 3D radiation stress model and implement another popular theory of the vortex force formulism to account for the wave effects on circulation in various numerical models (Kumar et al., 2011; Marsooli et al., 2017; Wang et al., 2017). The potential improvement of the 3D radiation stress theory and vortex force formulism applied to the wave-current model (e.g., simulating the rip current, surface onshore flow and bottom undertow in the surf zone) could be achieved by additional observations of the 3D current velocity profile in the surf zone.

\section{Acknowledgments}

This research was partially supported by the EPA Maryland Coastal Bays Program and NSF CREST Center. The wave-current coupling process part benefits from discussion with Prof. George L. Mellor of the Princeton University, and members of the Physical Oceanography group of University of Oldenburg, Germany: Florian Hahner, Xue Wang, Dr. Karsten Lettmann, and Prof. Dr. Jörg-Olaf Wolff. The wave-current coupling code applied in this study was compared to the version of Dr. Karsten Lettmann and the version provided by Dr. Yongsheng Wu of Bedford Institute of Oceanography, Canada. The authors greatly appreciate four anonymous Reviewers and the Editor-in-Chief (Dr. W. Perrie) for their constructive comments that significantly improve the quality of this manuscript. Numerical experiments were carried out on the National Center for Atmospheric Research's Computational Information Systems Laboratory.

\section{Supplementary materials}

Supplementary material associated with this article can be found, in the online version, at doi:10.1016/j.ocemod.2018.08.002.

\section{Appendix}

List of acronyms and full names of the variables in alphabetical order

\begin{tabular}{ll}
\hline 3D/2D & Three/Two dimensional \\
APD & Absolute percentage difference \\
BSS & Brier skill score \\
CC & Pearson correlation coefficient \\
CI & Chincoteague Inlet \\
COAWST & Coupled-Ocean-Atmosphere-Wave-Sediment Transport \\
DWTF & Depth-integrated Water Transport Flux \\
FVCOM & Finite-Volume Community Ocean Model \\
MCBs & Maryland Coastal Bays \\
MWD & Mean Wave Direction \\
NAM & North American Mesoscale Model \\
NARR & North American Regional Reanalysis \\
NCEI & National Centers for Environmental Information \\
NDBC & National Data Buoy Center \\
NHC & National Hurricane Center \\
NOAA & National Oceanic and Atmospheric Administration \\
OCI & Ocean City Inlet \\
PWP & Peak wave period \\
RB & Relative bias \\
RMSD & Root-mean-square deviation \\
SWAVE & Surface wave model \\
SWH & Significant wave height \\
USGS & United States Geological Survey \\
WIS & Wave information studies \\
WISWAVE & Wave information studies wave model \\
WS & Willmott skill \\
WSE & Water surface elevation \\
\hline & \\
\hline
\end{tabular}

\section{References}

Allen, T.R., Tolvanen, H.T., Oertel, G.F., Mcleod, G.M., 2007. Spatial characterization of environmental gradients in a coastal lagoon, Chincoteague Bay. Estuaries Coasts 30 (6), 959-977.

Apotsos, A., Raubenheimer, B., Elgar, S., Guza, R.T., 2008. Wave-driven setup and alongshore flows observed onshore of a submarine canyon. J. Geophys. Res. 113,
C07025. https://doi.org/10.1029/2007JC004514.

Ardhuin, F., Hamon, M., Collard, F., Chapron, B., Queffeulou, P., 2008. Spectral wave evolution and spectral dissipation based on observations: a global validation of new source functions. In: Proceedings, 4th Chinese-German Joint Symposium on Coastal and Ocean Engineering. Darmstadt, Germany.

Ardhuin, F., Suzuki, N., McWilliams, J.C., Aiki, H., 2017. Comments on "A combined derivation of the integrated and vertically resolved, coupled wave-current equations". J. Phys. Oceanogr. 47 (9), 2377-2385. 
Avila, L.A., Cangialosi, J., 2011. Hurricane Irene (AL092011) 21-28 August 2011 Tropical Cyclone Rep 1-45.

Battjes, J.A., Janssen, J.P.F.M., 1978. Energy loss and set-up due to breaking of random waves. In: Coastal Engineering, pp. 569-588 Am. Soc. Civ. Eng. N.Y.

Benetazzo, A., Carniel, S., Sclavo, M., Bergamasco, A., 2013. Wave-current interaction: effect on the wave field in a semi-enclosed basin. Ocean Modell. 70, 152-165.

Bertin, X., Fortunato, A.B., Oliveira, A., 2009. A modeling-based analysis of processes driving wave-dominated inlets. Cont. Shelf Res. 29 (5-6), 819-834.

Beudin, A., Ganju, N.K., Defne, Z., Aretxabaleta, A.L., 2017. Physical response of a backbarrier estuary to a post-tropical cyclone. J. Geophys. Res. 122, 5888-5904.

Bolaños, R., Osuna, P., Wolf, J., Monbaliu, J., Sanchez-Arcilla, A., 2011. Development of the POLCOMS-WAM wave-current model. Ocean Modell. 36 (1-2), 102-115.

Booij, N., Ris, R.C., Holthuijsen, L.H., 1999. A third-generation wave model for coastal regions: 1. Model description and validation. J. Geophys. Res. 104 (C4), 7649-7666.

Boynton, W.R., Murray, L., Hagy, J.D., Stokes, C., Kemp, W.M., 1996. A comparative analysis of eutrophication patterns in a temperate coastal lagoon. Estuaries 19 (2), 408-421.

Boynton, W.R., Murray, L., Kemp, W.M., Hagy, J.D., Stokes, C., Jacobs, F., Seibel, J., 1993. Maryland's Coastal Bays: An Assessment of Aquatic Ecosystems, Pollutant Loadings, and Management Options. Maryland Department of the Environment, Baltimore, MD.

Brier, G.W., 1950. Verification of forecasts expressed in terms of probability. Mon. Weather Rev. 78, 1-3.

Chen, C., Beardsley, R.C., Cowles, G., Qi, J., Lai, Z., Gao, G., Stuebe, D., Liu, H., Xu, Q., Xue, P., Ge, J., Ji, R., Hu, S., Tian, R., Huang, H., Wu, L., Lin, H., Sun, Y., Zhao, L., 2013. An Unstructured-Grid, Finite-Volume Community Ocean Model FVCOM User Manual, third ed., SMAST/UMASSD Tech. Rep.-13-0701. Univ. of Mass.-Dartmouth, New Bedford, Massachusetts, pp. 404.

Chen, J.-L., Hsu, T.-J., Shi, F., Raubenheimer, B., Elgar, S., 2015. Hydrodynamic and sediment transport modeling of New River Inlet (NC) under the interaction of tides and waves. J. Geophys. Res. 120, 4028-4047.

Craik, A.D., Leibovich, S., 1976. A rational model for Langmuir circulation. J. Fluid Mech. 73 (3), 401-426.

Defne, Z., Ganju, N.K., 2015. Quantifying the residence time and flushing characteristics of a shallow, back-barrier estuary: application of hydrodynamic and particle tracking models. Estuaries Coasts 38 (5), 1719-1734.

Department of Natural Resources, Maryland, 2011. Impacts of Hurricane Irene on Maryland's Coastal Bays. Available at. http://mddnr.chesapeakebay.net.

Dietrich, J.C., Zijlema, M., Allier, P.-E., Holthuijsen, L.H., Booij, N., Meixner, J.D., Proft, J.K., Dawson, C.N., Bender, C.J., Naimaster, A., Smith, J.M., Westerink, J.J., 2013. Limiters for spectral propagation velocities in SWAN. Ocean Modell. 70, 85-102.

Dillow, J.J., Greene, E.A., 1999. Ground-Water Discharge and Nitrate Loadings to the Coastal Bays of Maryland. U.S. Dept. of the Interior, U.S. Geological Survey.

Dodet, G., Bertin, X., Bruneau, N., Fortunato, A.B., Nahon, A., Roland, A., 2013. Wave-current interactions in a wave-dominated tidal inlet. J. Geophys. Res. 118 (3), 1587-1605.

Donelan, M.A., Dobson, F.W., Smith, S.D., Anderson, R.J., 1993. On the dependence of sea surface roughness on wave development. J. Phys. Oceanogr. 23, 2143-2149.

Du, J., Bolaños, R., Larsén, X.G., 2017. The use of a wave boundary layer model in SWAN. J. Geophys. Res. 122. https://doi.org/10.1002/2016JC012104.

Duran-Matute, M., Gerkema, T., Sassi, M.G., 2016. Quantifying the residual volume transport through a multiple-inlet system in response to wind forcing: the case of the western Dutch Wadden Sea. J. Geophys. Res. 121 (12), 8888-8903.

Fabião, J.P.F., Rodrigues, M.F.G., Fortunato, A.B., de Brito Jacob, J.M.Q., Cravo, A.M.F., 2016. Water exchanges between a multiple-inlet lagoon and the ocean: the role of forcing mechanisms. Ocean Dyn. 66, 173-194.

Fan, Y., Ginis, I., Hara, T., 2009. The effect of wind-wave-current interaction on air-sea momentum fluxes and ocean response in tropical cyclones. J. Phys. Oceanogr. 39, 1019-1034.

Ferrarin, C., Bergamasco, A., Umgiesser, G., Cucco, A., 2013. Hydrodynamics and spatial zonation of the Capo Peloro coastal system (Sicily) through 3-D numerical modeling. J. Marine Syst. 117, 96-107.

Ganju, N.K., Suttles, S.E., Beudin, A., Nowacki, D.J., Miselis, J.L., Andrews, B.D., 2017. Quantification of storm-induced bathymetric change in a back-barrier estuary. Estuaries. Coasts 40 (1), 22-36.

Ge, J., Ding, P., Chen, C., Hu, S., Fu, G., Wu, L., 2013. An integrated East China Sea-Changjiang estuary model system with aim at resolving multi-scale regionalshelf-estuarine dynamics. Ocean Dyn. 63 (8), 881-900.

Grashorn, S., Lettmann, K.A., Wolff, J.O., Badewien, T.H., Stanev, E.V., 2015. East Frisian Wadden Sea hydrodynamics and wave effects in an unstructured-grid model. Ocean Dyn. 65 (3), 419-434.

Hayes, M.O., 1979. Barrier island morphology as a function of tidal and wave regime. In: Leatherman, S.P. (Ed.), Barrier Islands from the Gulf of St. Lawrence to the Gulf of Mexico. Academic Press, New York, pp. 28.

Holland, G.J., 1980. An analytic model of the wind and pressure profiles in hurricanes. Mon. Weather Rev. 108 (8), 1212-1218.

Hopkins, J., Elgar, S., Raubenheimer, B., 2016. Observations and model simulations of wave-current interaction on the inner shelf. J. Geophys. Res. 121, 198-208.

Hubertz, J.M., 1992. User's Guide to the Wave Information Studies (WIS) Wave Model: Version 2.0: Version 2.0. U.S. Army Engineer Waterways Experiment Station, Vicksburg, MS, pp. 28 WIS Report 27.

Ji, C., Zhang, Q., Wu, Y., 2018. An empirical formula for maximum wave setup based on a coupled wave-current model. Ocean Eng. 147, 215-226.

Kang, X., Xia, M., Pitula, J.S., Chigbu, P., 2017. Dynamics of water and salt exchange at Maryland Coastal Bays. Estuaries Coasts Shelf Sci. 189, 1-16.

Klausmann, A.M., 2014. Analysis of Hurricane Irene's Wind Field using the advanced research weather research and forecast (WRF-ARW) Model. J. Mar. Sci. Eng. 2 (1), $33-45$.

Komen, G.J., Hasselmann, S., Hasselmann, K., 1984. On the existence of a fully developed wind-sea spectrum. J. Phys. Oceanogr. 14 (8), 1271-1285.

Krantz, D.E., Schupp, C.A., Spaur, C.C., Thomas, J.E., Wells, D.V., 2009. Dynamic Systems at the Land-Sea Interface, Shifting Sands: Environmental and Cultural Change in Maryland's Coastal Bays. Univ. of Maryland Center for Environmental Sciences, IAN Press, Cambridge, MD, pp. 211-248.

Kumar, N., Voulgaris, G., Warner, J.C., 2011. Implementation and modification of a threedimensional radiation stress formulation for surf zone and rip-current applications. Coastal Eng. 58, 1097-1117.

Kumar, N., Voulgaris, G., Warner, J.C., Olabarrieta, M., 2012. Implementation of the vortex force formalism in the coupled ocean-atmosphere-wave-sediment transport (COAWST) modeling system for inner shelf and surf zone applications. Ocean Modell. 47, 65-95.

Lane, E.M., Restrepo, J.M., McWilliams, J.C., 2007. Wave-current interaction: A comparison of radiation-stress and vortex-force representations. J. Phys. Oceanogr. 37 (5), 1122-1141.

Large, W.G., Pond, S., 1981. Open ocean momentum flux measurements in moderate to strong winds. J. Phys. Oceanogr. 11 (3), 324-336.

Lentz, S.J., Churchill, J.H., Davis, K.A., Farrar, J.T., Pineda, J., Starczak, V., 2016. The characteristics and dynamics of wave-driven flow across a platform coral reef in the Red Sea. J. Geophys. Res. 121, 1360-1376.

Lentz, S.J., Guza, R.T., Elgar, S., Feddersen, F., Herbers, T.H.C., 1999. Momentum balances on the North Carolina inner shelf. J. Geophys. Res. 104 (C8), 18205-18226.

Lentz, S.J., Raubenheimer, B., 1999. Field observations of wave setup. J. Geophys. Res. 104 (C11), 25867-25875.

Lin, R.Q., Perrie, W., 2003. Wave-current interactions in an idealized tidal estuary. J. Geophys. Res. 108, 3023. https://doi.org/10.1029/2001JC001006. C2.

Liu, H., Xie, L., 2009. A numerical study on the effects of wave-current-surge interactions on the height and propagation of sea surface waves in Charleston Harbor during Hurricane Hugo 1989. Cont. Shelf Res. 29 (11-12), 1454-1463.

Longuet-Higgins, M.S., 1970. Longshore currents generated by obliquely incident sea waves, 1 and 2. J. Geophys. Res. 75, 6778-6801.

Longuet-Higgins, M.S., Stewart, R.W., 1964. Radiation stresses in water waves; a physical discussion, with applications. Deep Sea Res. 11, 529-562.

Lowe, R.J., Falter, J.L., Monismith, S.G., Atkinson, M.J., 2009. Wave-driven circulation of a coastal reef-lagoon system. J. Phys. Oceanogr. 39 (4), 873-893.

Madsen, O.S., 1994. Spectral wave-current bottom boundary layer flows. In: Coastal Engineering 1994. Proceedings of the 24th Internal Conference on Coastal Engineering Research Council. Kobe, Japan. pp. 384-398.

Malhadas, M.S., Leitão, P.C., Silva, A., Neves, R., 2009. Effect of coastal waves on sea level in Óbidos Lagoon, Portugal. Cont. Shelf Res. 29 (9), 1240-1250.

Mao, M., Xia, M., 2017. Dynamics of wave-current-surge interactions in Lake Michigan: a model comparison. Ocean Modell. 110, 1-20.

Marsooli, R., Orton, P.M., Mellor, G., Georgas, N., Blumberg, A.F., 2017. A coupled circulation-wave model for numerical simulation of storm tides and waves. J. Atmos. Ocean Tech. 34 (7), 1449-1467.

McWilliams, J.C., Restrepo, J.M., Lane, E.M., 2004. An asymptotic theory for the interaction of waves and currents in coastal waters. J. Fluid Mech. 511, 135-178.

Mei, C.C., 1983. The Applied Dynamics of Ocean Surface Waves. Wiley, New York, pp. 740.

Mellor, G.L., 2005. Some consequences of the three-dimensional current and surface wave equations. J. Phys. Oceanogr. 35 (11), 2291-2298.

Mellor, G.L., 2008. The depth-dependent current and wave interaction equations: a revision. J. Phys. Oceanogr. 38, 2587-2596.

Mellor, G.L., 2013. Waves, circulation and vertical dependence. Ocean Dyn. 63 (4), 447-457.

Mellor, G.L., 2015. A combined derivation of the integrated and vertically resolved, coupled wave-current equations. J. Phys. Oceanogr. 45 (6), 1453-1463.

Mellor, G.L., 2016. On theories dealing with the interaction of surface waves and ocean circulation. J. Geophys. Res. 121 (7), 4474-4486.

Mellor, G.L., 2017. Reply to "Comments on 'A combined derivation of the integrated and vertically resolved, coupled wave-current equations'”. J. Phys. Oceanogr. 47 (9), 2387-2389.

Moghimi, S., Klingbeil, K., Gräwe, U., Burchard, H., 2013. A direct comparison of a depthdependent radiation stress formulation and a vortex force formulation within a threedimensional coastal ocean model. Ocean Modell. 70, 132-144.

Munk, J., Munk, W., 1972. Venice hologram. Proc. Am. Philos. Soc. 116 (5), 415-442.

Niu, Q., Xia, M., 2017. The role of wave-current interaction in Lake Erie's seasonal and episodic dynamics. J. Geophys. Res. 122, 7291-7311.

Niu, Q., Xia, M., Ludsin, S.A., Chu, P.Y., Mason, D.M., Rutherford, E.S., 2018. High-turbidity events in western Lake Erie during ice-free cycles: contributions of river-loaded versus resuspended sediments. Accepted by Limnol. Oceanogr.

Olabarrieta, M., Warner, J.C., Kumar, N., 2011. Wave-current interaction in Willapa Bay. J. Geophys. Res. 116, C12014. https://doi.org/10.1029/2011JC007387.

Orescanin, M., Raubenheimer, B., Elgar, S., 2014. Observations of wave effects on inlet circulation. Cont. Shelf Res. 82, 37-42.

Pacheco, A., Ferreira, Ó., Williams, J.J., Garel, E., Vila-Concejo, A., Dias, J.A., 2010. Hydrodynamics and equilibrium of a multiple-inlet system. Mar. Geol. 274 (1), 32-42.

Panchang, V.G., Jeong, C., Li, D., 2008. Wave climatology in coastal Maine for aquaculture and other applications. Estuaries Coasts 31 (2), 289-299.

Pawlowicz, R., Beardsley, B., Lentz, S., 2002. Classical tidal harmonic analysis including error estimates in MATLAB using T_TIDE. Comput. Geosci. 28 (8), 929-937.

Perrie, W., Tang, C.L., Hu, Y., DeTracy, B.M., 2003. The impact of waves on surface 
currents. J. Phys. Oceanogr. 33 (10), 2126-2140.

Phillips, O.M., 1977. The Dynamics of the Upper Ocean. Cambridge University Press, pp. 336.

Pritchard, D.W., 1960. Salt balance and exchange rate for Chincoteague Bay. Chesapeake Sci. 1 (1), 48-57.

Purkiani, K., Becherer, J., Flöser, G., Gräwe, U., Mohrholz, V., Schuttelaars, H.M., Burchard, H., 2015. Numerical analysis of stratification and destratification processes in a tidally energetic inlet with an ebb tidal delta. J. Geophys. Res. 120 (1), 225-243.

Qi, J., Chen, C., Beardsley, R.C., Perrie, W., Cowles, G.W., Lai, Z, 2009. An unstructuredgrid finite-volume surface wave model (FVCOM-SWAVE): implementation, validations and applications. Ocean Modell. 28, 153-166.

Salmon, J.E., Holthuijsen, L.H., Zijlema, M., van Vledder, G.Ph., Pietrzak, J.D., 2015 Scaling depth-induced wave-breaking in two-dimensional spectral wave models. Ocean Modell. 87, 30-47.

Sheng, Y.P., Liu, T., 2011. Three-dimensional simulation of wave-induced circulation: comparison of three radiation stress formulations. J. Geophys. Res. 116, C05021. https://doi.org/10.1029/2010JC006765.

Soulsby, R., 1997. Dynamics of Marine Sands. A Manual For Practical Applications. Thomas Telford Publishing, London.

Spydell, M.S., Feddersen, F., Olabarrieta, M., Chen, J., Guza, R.T., Raubenheimer, B., Elgar, S., 2015. Observed and modeled drifters at a tidal inlet. J. Geophys. Res. 120 (7), 4825-4844.

Svendsen, I.A., 1984. Wave heights and set-up in a surf zone. Coastal Eng. 8 (4), 303-329.

Svendsen, I.A., Haas, K., Zhao, Q., 2002. Quasi-3D Nearshore Circulation Model SHORECIRC, User's Manual. Center for Applied Coastal Research, Department of Civil Engineering, University of Delaware, Newark.

SWAN Group, 2012. SWAN User Manual-SWAN Cycle III Version 40.91. chap. 2. Delft Univ. of Technol., Delft, Netherlands, pp. 7-40.

Umgiesser, G., Ferrarin, C., Cucco, A., De Pascalis, F., Bellafiore, D., Ghezzo, M., Bajo, M., 2014. Comparative hydrodynamics of 10 Mediterranean lagoons by means of numerical modeling. J. Geophys. Res. 119, 2212-2226.

Van der Westhuysen, A.J., 2010. Modeling of depth-induced wave breaking under finite depth wave growth conditions. J. Geophys. Res. 115, C01008. https://doi.org/10.
1029/2009JC005433.

Van der Westhuysen, A.J., van Dongeren, A.R., Groeneweg, J., van Vledder, G.Ph., Peters, H., Gautier, C., van Nieuwkoop, J.C.C., 2012. Improvements in spectral wave modeling in tidal inlet seas. J. Geophys. Res. 117, C00J28. https://doi.org/10.1029/ 2011JC007837.

Wang, P., Sheng, J., Hannah, C., 2017. Assessing the performance of formulations for nonlinear feedback of surface gravity waves on ocean currents over coastal waters. Cont. Shelf Res. 146, 102-117.

Warner, J.C., Sherwood, C.R., Signell, R.P., Harris, C.K., Arango, H.G., 2008. Development of a three-dimensional, regional, coupled wave, current, and sedimenttransport model. Comput. Geosci. 34 (10), 1284-1306.

Wargula, A., Raubenheimer, B., Elgar, S., 2014. Wave-driven along-channel subtidal flows in a well-mixed ocean inlet. J. Geophys. Res. 119 (5), 2987-3001.

Wazniak, C., Wells, D.V., Hall, M., 2005. The Maryland coastal Bays ecosystem: Ecosystem Health Assessment 2004. Maryland Dept. of Natural Resources, Tidewater Ecosystem Assessment, Annapolis, MD.

Whitham, G.B., 1974. Linear and Nonlinear Waves. Wiley, New York, pp. 636.

Willmott, C.J., 1981. On the validation of models. Phys. Geogr. 2 (2), 184-194.

Wolf, J., Prandle, D., 1999. Some observations of wave-current interaction. Coastal Eng. 37 (3-4), 471-485.

Xia, M., Xie, L., Pietrafesa, L.J., Peng, M., 2008. A numerical study of storm surge in the Cape Fear River Estuary and adjacent coast. J. Coastal Res. 24, 159-167.

Xia, M., Xie, L., Pietrafesa, L.J., Whitney, M.M., 2011. The ideal response of a Gulf of Mexico estuary plume to wind forcing: Its connection with salt flux and a Lagrangian view. J. Geophys. Res. 116, C08035. https://doi.org/10.1029/2010JC006689.

Xie, L., Pietrafesa, L.J., Wu, K., 2003. A numerical study of wave-current interaction through surface and bottom stresses: coastal ocean response to Hurricane Fran of 1996. J. Geophys. Res. 108, 3049. https://doi.org/10.1029/2001JC001078. C2.

Xu, F., Perrie, W., Solomon, S., 2013. Shallow water dissipation processes for wind waves off the Mackenzie Delta. Atmos. Ocean 51 (3), 296-308.

Zedler, J.B., Callaway, J.C., Sullivan, G., 2001. Declining biodiversity: why species matter and how their functions might be restored in Californian tidal marshes. Bioscience 51, 1005-1017. 